\title{
A Review of the Pathophysiology and Potential Biomarkers for Peripheral Artery Disease
}

\section{Smriti Murali Krishna ${ }^{1}$, Joseph V. Moxon ${ }^{1}$ and Jonathan Golledge ${ }^{1,2, *}$}

1 The Vascular Biology Unit, Queensland Research Centre for Peripheral Vascular Disease, College of Medicine \& Dentistry, James Cook University, Townsville, QLD 4811, Australia; E-Mails: smriti.krishna@jcu.edu.au (S.M.K.); joseph.moxon@jcu.edu.au (J.V.M.)

2 Department of Vascular and Endovascular Surgery, the Townsville Hospital, Townsville, QLD 4810, Australia

* Author to whom correspondence should be addressed; E-Mail: jonathan.golledge@jcu.edu.au; Tel.: +61-7-4796-1417; Fax: +61-7-4796-1401.

Academic Editor: Johannes Haybaeck

Received: 16 February 2015 / Accepted: 8 April 2015 / Published: 18 May 2015

\begin{abstract}
Peripheral artery disease (PAD) is due to the blockage of the arteries supplying blood to the lower limbs usually secondary to atherosclerosis. The most severe clinical manifestation of PAD is critical limb ischemia (CLI), which is associated with a risk of limb loss and mortality due to cardiovascular events. Currently CLI is mainly treated by surgical or endovascular revascularization, with few other treatments in routine clinical practice. There are a number of problems with current PAD management strategies, such as the difficulty in selecting the appropriate treatments for individual patients. Many patients undergo repeated attempts at revascularization surgery, but ultimately require an amputation. There is great interest in developing new methods to identify patients who are unlikely to benefit from revascularization and to improve management of patients unsuitable for surgery. Circulating biomarkers that predict the progression of PAD and the response to therapies could assist in the management of patients. This review provides an overview of the pathophysiology of PAD and examines the association between circulating biomarkers and PAD presence, severity and prognosis. While some currently identified circulating markers show promise, further larger studies focused on the clinical value of the biomarkers over existing risk predictors are needed.
\end{abstract}


Keywords: peripheral artery disease; critical limb ischemia; biomarkers; angiogenesis; arteriogenesis

\section{Introduction}

Narrowing or blockage of the arteries supplying blood to the lower limbs, usually termed peripheral artery disease (PAD), is principally caused by athero-thrombosis. PAD is a leading cause of morbidity due to the associated functional decline and limb loss. Both asymptomatic and symptomatic PAD are significant predictors of cardiovascular disease (CVD) events and mortality [1]. Current evidence suggests that PAD represents a CVD risk equivalent to or worse than coronary artery disease requiring aggressive medical management [2].

The main recognized clinical presentations of PAD are intermittent claudication (IC) and critical limb ischemia (CLI). IC describes the symptoms of pain in the muscles of the lower limb brought on by physical activity which is rapidly relieved by rest. CLI is a more severe manifestation of PAD, which presents as rest pain, ischemic ulceration or gangrene of the foot. Patients with CLI have a high risk of limb loss and fatal or non-fatal vascular events, such as myocardial infarction (MI) and stroke [2]. Acute limb ischemia (ALI) occurs when there is a sudden interruption of blood flow to a limb typically due to an embolism or thrombosis [3]. In contrast to CLI, which typically develops over a prolonged period often preceded by IC, patients with ALI may not have preceding symptoms. ALI usually threatens limb viability more urgently than CLI possibly due to the absence of an established collateral blood supply to the limb.

\section{Epidemiology of PAD}

The prevalence of PAD is estimated to be $10 \%-25 \%$ in people aged $\geq 55$ years and increases to approximately $40 \%$ in community populations aged $>80$ years [4,5]. Approximately $4-8$ million people are affected by PAD in the United States of America [6-8]. In Germany around 1.8 million people have symptomatic PAD and each year between 50,000 to 80,000 patients develop CLI [9,10]. In a population-based study in Western Australia, the prevalence of PAD was reported to be approximately $23 \%$ in men aged 75-79 years [4]. Recent reports suggest that the burden of PAD has increased globally over the last decade [11-13]. Atherosclerosis induced CLI has been associated with a mortality rate of $20 \%-25 \%$ in the first year after presentation and a survival rate of less than $30 \%$ at five years [14-19]. Previous reports suggest that CLI patients have a three-year limb loss rate of about $40 \%$ [20-23].

Recurrent CLI due to the failure of lower extremity revascularization is associated with a poor outcome [24,25]. In the Bypass versus Angioplasty in Severe Ischemia of the Leg (BASIL, $n=216$ ) trial, the re-intervention rate in 216 patients with CLI treated by percutaneous transluminal angioplasty was $26 \%$ at 12 months [14]. Reasons for revascularization failure include restenosis, and residual and progressive atherosclerosis. Approximately $20 \%-30 \%$ of CLI patients are not ideal candidates for interventional procedures for a number of reasons such as the distribution of the occlusive disease and the patient's co-morbidities [26]. Patients with CLI represent a small subset of the total PAD population 
however the high incidence of CVD events, repeated requirement for medical attention and high amputation rates lead to significant health service costs associated with these individuals [27,28]. Improvements in the current management of PAD are needed on many levels including earlier diagnosis, development of novel effective therapies and better application of currently available treatments.

\section{Risk Factors for PAD}

Approximately $70 \%$ of PAD cases can be explained by established risk factors such as older age, hypertension, dyslipidemia, cigarette smoking and diabetes [29]. It has been reported that for every $1 \%$ increase in hemoglobin A1c there is a corresponding 26\% increase in PAD risk [30]. Insulin resistance has been identified as a risk factor for PAD even in subjects without diabetes [31]. The association between sex and PAD is less clear. The prevalence of asymptomatic or symptomatic PAD is slightly greater in men than in women and the incidence increases with increasing age [17]. Women have been reported to have a more advanced CLI stage at presentation (odds ratio (OR), 1.21; 95\% confidence interval (CI): 1.21-1.23) [32]. Black ethnicity has been reported to increase the risk of PAD by over two fold [17]. There is also reported to be an association between underserved communities and major amputations due to PAD (adjusted OR, 1.29, 95\% CI: 1.16-1.44) [33]. Cigarette smoking has been strongly associated with PAD incidence and heavy smokers have a four-fold higher risk of developing IC compared to non-smokers [17]. PAD thus shares risk factors with other CVDs, such as coronary artery disease, however some risk factors, such as smoking, are more powerfully associated with PAD than other CVDs.

\section{Current PAD Management Strategies}

PAD management focuses in part on the reduction of CVD risk factors [34,35]. A number of lower extremity performance measures have been suggested as prognostic markers in PAD and may be useful to identify patients at increased mortality risk [36]. Supervised exercise programs have been established as effective ways to increase pain free walking distance among patients with IC although they are not widely implemented [36]. Other medical therapies are applied to control pain, treat infection and promote ulcer healing. Revascularization, via endovascular means (e.g., percutaneous transluminal angioplasty or stenting) or open surgery (e.g., bypass), is the main treatment option for patients with CLI. Up to $30 \%$ of patients are not considered ideal for such interventions [26], the main reasons being unfavorable vascular involvement and peri-operative risk [37]. Previous studies suggest that endovascular and open surgical therapies provide similar outcomes for CLI. A recent meta-analysis of 23 studies reported no difference in amputation-free survival at three years (OR, 1.22, 95\% CI: 0.84-1.77) and all-cause mortality (OR, 1.07, 95\% CI: 0.73-1.56) in patients with CLI treated by endovascular or surgical revascularization [38].

There is current interest in the development of novel therapies to improve arteriogenesis (collateral formation) and/or angiogenesis (capillary formation) in patients with PAD [19]. A number of approaches are currently being investigated including gene therapies and cell-based therapies [26,39,40]. It was reported for example that intramuscular injection of autologous bone marrow mononuclear cells resulted in a three-year amputation free rate of $60 \%$ with significant improvement in ischemic leg pain and walking distance in the therapeutic angiogenesis by cell transplantation (TACT) trial [41]. 
In another recent trial, the use of tissue repair cells in patients with PAD (RESTORE-CLI), it was reported that administration of patient-derived bone marrow mononuclear cells led to an amputation free survival improvement of 32\% [42]. These novel therapeutic approaches are promising strategies for CLI patients who are not ideal candidates for traditional revascularization procedures.

\section{The Pathophysiological Response to Athero-Thombosis-Induced PAD}

PAD is mainly caused by atherosclerosis and associated thrombosis within the lower limb arteries leading to end organ ischemia. Other causes include vasculitis and in situ thrombosis related to hypercoagulable states. The pathophysiology of athero-thrombosis induced PAD is complex, and involves a large number of cells, proteins and pathways. Important cells contributing to or controlling the development of athero-thrombosis include vascular endothelial cells (ECs), vascular smooth muscle cells (SMCs), fibroblasts, platelets, resident stem cells, pericytes and inflammatory cells [43-45]. The pathophysiology of atherosclerosis has been described in detail in previous reviews [46-48].

Under healthy conditions the response to gradually progressive limb ischemia involves the promotion of angiogenesis and arteriogenesis in an attempt to increase the blood supply to the affected limb. Vascular remodeling, inflammation and apoptotic pathways are also implicated in the ischemic response and these may in part contribute to the resolution of tissue damage. In patients with CLI these compensatory responses to ischemia are ineffective. As a result, there is on-going inadequate perfusion of tissue, endothelial dysfunction, chronic inflammation and high levels of oxidative stress. All these changes lead to mitochondrial injury, free radical generation, muscle fibre damage, myofibre degeneration and fibrosis, and tissue damage, which may present as gangrene [49-53] (Figure 1).

Arteriogenesis is the process of enlargement of pre-existing collateral arteries to contribute to tissue perfusion [54]. The primary driving force is the increased laminar blood flow or shear stress associated with redistribution of flow as a result of the reduction in downstream luminal pressure. The increase in shear stress promotes vessel enlargement [55], which is stimulated by activation of nitric oxide (NO) signaling and likely other signaling responses to flow [56,57]. Angiogenesis describes the development of new capillary networks. An important driving force for angiogenesis is tissue ischemia. In response to local hypoxia in the ischemic limb, sprouting of small endothelial tubes occurs from pre-existing capillary beds. A number of hypoxia-inducible growth factors play a role in this process, such as vascular endothelial growth factor (VEGF) and hypoxia inducible factor (HIF)-1 $\alpha$ [58] (Figure 1).

Potential therapies designed to accelerate arteriogenesis and angiogenesis during ischemia are under intense investigation although most of these interventions have not developed to a stage that they are ready for widespread clinical use [59-62]. 


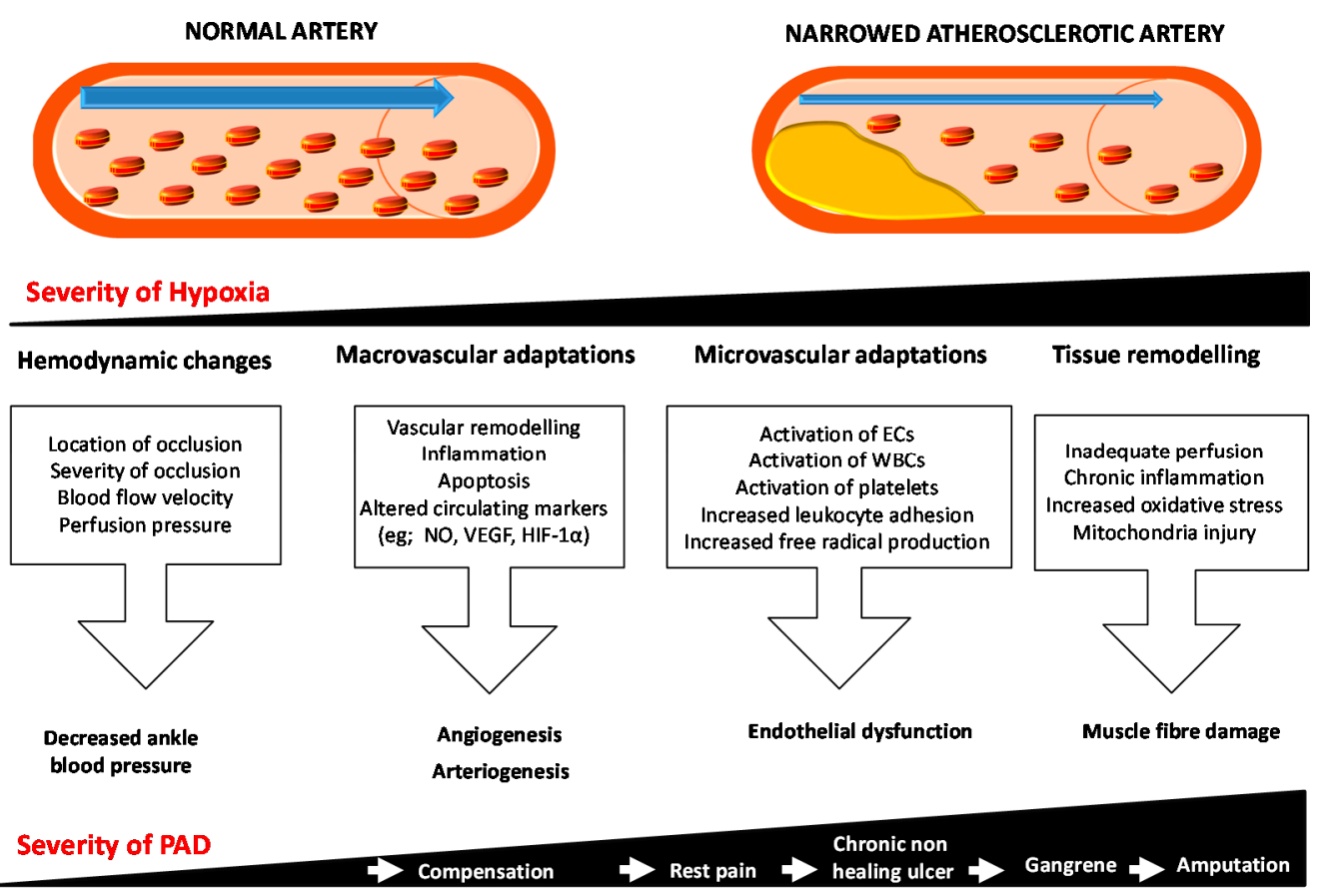

Figure 1. Schematic representation of the response to ischemia in peripheral artery disease. Initially the ischemic limb tries to compensate and resolve the hypoxia by changing the hemodynamics and promoting microvascular adaptations by promoting angiogenesis and/or arteriogenesis. As the severity of the hypoxia increases, the microvascular adaptations are not able to compensate. All these changes lead to mitochondrial injury and free radical generation and subsequent muscle fibre damage, myofibre degeneration and fibrosis. These changes eventually result in decreased oxygen supply and increased metabolic demands leading to conditions such as rest pain, chronic non-healing wounds and gangrene, subsequently threatening the limb function and viability. Blue arrows show the direction of blood flow in the artery and white arrows shows the increase in severity of disease. Abbreviations: ECs, endothelial cells; HIF-1 $\alpha$, Hypoxia inducible factor-1 $\alpha$; NO, Nitric oxide; PAD, Peripheral artery disease; VEGF, Vascular endothelial growth factor WBCs, white blood cells.

\section{Potential Biomarkers for PAD}

PAD is usually diagnosed using clinical assessment, ankle brachial pressure index (ABI) measurement or radiological imaging, or both, depending on the setting of the patient. Each of these approaches has advantages and disadvantages. ABI for example is a simple and cheap investigation to diagnose PAD but not applied frequently in routine practice $[63,64]$. Patients with IC alone typically have an ABI of 0.5-0.9, while CLI patients usually have an ABI of $<0.4$ [23]. Angiography provides detailed imaging of the lower limb arteries but it is more expensive and involves exposure to radiation. The introduction of circulating markers which can diagnose PAD or predict patient outcomes has been suggested as a means to overcome some of the limitations of current approaches.

A range of circulating markers of atherosclerosis, arterial stiffness, inflammation, angiogenesis, vascular extra cellular matrix (ECM) remodeling, endothelial dysfunction and oxidative stress have been reported to be associated with PAD. Some of these biomarkers have also been suggested to be useful in predicting disease severity and prognosis. 


\subsection{Circulating Markers Associated with the Presence of PAD}

Case-control studies have reported the association of a number of circulating markers with PAD presence (Table 1).

Table 1. Examples of circulating biomarkers reported to be associated with peripheral artery disease.

\begin{tabular}{|c|c|c|c|c|}
\hline $\begin{array}{c}\text { Circulating } \\
\text { Biomarkers Assessed }\end{array}$ & Sample Size $(N)$ & $\begin{array}{l}\text { Sample } \\
\text { Studied }\end{array}$ & Association with PAD Presence & Refs. \\
\hline B2M \& cystatin C & $\begin{array}{l}\text { CAD \& PAD (197); CAD (81) } \\
\text { \& healthy controls }(262)\end{array}$ & Plasma & $\begin{array}{l}\text { A biomarker panel comprising } \mathrm{B} 2 \mathrm{M} \text {, } \\
\text { cystatin } \mathrm{C}, \mathrm{hsCRP} \text { and glucose were } \\
\text { associated with PAD. }\end{array}$ & {$[65]$} \\
\hline $\begin{array}{l}\text { B2M, cystatin C, } \\
\text { hsCRP \& glucose }\end{array}$ & PAD (83) \& controls (896) & Plasma & $\begin{array}{l}\text { Levels of cystatin C and B2M but not } \\
\text { hsCRP and glucose were significantly } \\
\text { elevated in PAD patients. }\end{array}$ & [66] \\
\hline aPWV, AIx \& B2M & PAD (66) \& healthy controls (66) & Plasma & $\begin{array}{l}\mathrm{B} 2 \mathrm{M}, \text { aPWV and AIx were } \\
\text { significantly increased in patients with } \\
\text { PAD; among patients with PAD } \\
\text { elevated B2M levels were } \\
\text { independently associated with higher } \\
\text { aortic stiffness. }\end{array}$ & [67] \\
\hline $\begin{array}{l}\text { hsCRP, fibrinogen \& } \\
\text { leukocyte count }\end{array}$ & $\begin{array}{l}\text { The National Health and Nutrition } \\
\text { Examination Survey } 1999-2002 \\
\text { (4787 participants aged } \geq 40 \text { years) }\end{array}$ & Blood & $\begin{array}{l}\text { All } 3 \text { markers were independently } \\
\text { associated with PAD. }\end{array}$ & {$[68]$} \\
\hline hsCRP & PAD (82) \& healthy controls (41) & Plasma & Increased hsCRP levels in PAD patients. & [69] \\
\hline $\begin{array}{l}\text { CD40 ligand, } \\
\text { fibrinogen, Lp-PLA2, } \\
\text { osteoprotegerin, } \\
\text { P-selectin, and TNF-R2, } \\
\text { hsCRP, ICAM-1, IL-6, } \\
\text { MCP-1 \& MPO }\end{array}$ & $\begin{array}{l}\text { Framingham Offspring } \\
\text { Study participants (2800) }\end{array}$ & Plasma & $\begin{array}{l}\text { IL-6 \&TNF-R2 were associated } \\
\text { with PAD independent of established } \\
\text { risk factors. }\end{array}$ & {$[70]$} \\
\hline $\begin{array}{c}\text { VEGF-A, } \\
\text { TNF- } \alpha \& \text { IL-8 }\end{array}$ & PAD (130) \& controls $(36)$ & Serum & $\begin{array}{l}\text { Lower VEGF-A and higher TNF- } \alpha \text { \& } \\
\text { IL-8 in PAD patients. }\end{array}$ & [71] \\
\hline $\begin{array}{l}\text { High molecular } \\
\text { weight \& total } \\
\text { adiponectin }\end{array}$ & PAD (110) \& healthy controls (230) & Plasma & Lower adiponectin in women with PAD. & [72] \\
\hline OxPL/ApoB \& Lp-a & $\begin{array}{l}\text { Men with PAD (143), women with } \\
\text { PAD (144) \& controls (432) }\end{array}$ & Plasma & $\begin{array}{l}\text { Increased levels of OxPL/ApoB and } \\
\text { Lp-a were associated with PAD. }\end{array}$ & {$[73]$} \\
\hline Lp-PLA2 activity & PAD (172) \& healthy controls (787) & Plasma & $\begin{array}{l}\text { Increased Lp-PLA2 activity in } \\
\text { PAD patients. }\end{array}$ & [74] \\
\hline Lp-PLA2 level & PAD (145) \& healthy controls (837) & Plasma & $\begin{array}{l}\text { Lp-PLA2 levels were significantly } \\
\text { associated with PAD. }\end{array}$ & {$[75]$} \\
\hline NOx \&, sNOX2-dp & PAD (50) \& healthy controls (50) & Serum & $\begin{array}{l}\text { NOX2 up-regulation is associated with } \\
\text { artery dysfunction in PAD. }\end{array}$ & [76] \\
\hline NO & PAD (82) \& healthy controls (41) & Plasma & $\begin{array}{l}\text { Increased NO levels \& hsCRP levels } \\
\text { in PAD patients. }\end{array}$ & [69] \\
\hline TBARS \& ICAM-1 & PAD (31) \& healthy controls (10) & Plasma & Increased in PAD. & [77] \\
\hline
\end{tabular}


Table 1. Cont.

\begin{tabular}{|c|c|c|c|c|}
\hline $\begin{array}{c}\text { Circulating } \\
\text { Biomarkers Assessed }\end{array}$ & Sample Size $(N)$ & $\begin{array}{l}\text { Sample } \\
\text { Studied }\end{array}$ & Association with PAD Presence & Refs. \\
\hline Rho-kinase activity & $\begin{array}{c}\text { PAD (40), combined CAD/PAD (40) \& } \\
\text { healthy controls }(40)\end{array}$ & $\begin{array}{l}\text { Circulating } \\
\text { leukocytes }\end{array}$ & Increased in PAD. & [78] \\
\hline HCgp-39 & PAD (316) \& healthy controls (39) & Plasma & $\begin{array}{l}\text { Median levels of HCgp-39 were } \\
\text { significantly higher in PAD patients. }\end{array}$ & {$[79]$} \\
\hline CD163 \& TWEAK & PAD (155) \& healthy controls (251) & Plasma & $\begin{array}{l}\text { Decreased TWEAK level and higher } \\
\text { sCD163 levels in PAD patients. }\end{array}$ & [80] \\
\hline PON-3 & PAD (118), CAD (72) \& healthy controls (175) & Serum & Increased in PAD. & [81] \\
\hline $\begin{array}{l}\text { IL-6, E-selectin, } \\
\text { MMP-2, MMP-9 \& } \\
\text { TGF- } \beta 1\end{array}$ & PAD (80) \& healthy controls (3076) & Plasma & $\begin{array}{l}\text { Increased levels of IL- } 6 \text {, E-selectin, } \\
\text { MMP- } 2 \text { \& MMP- } 9 \text { and reduced levels } \\
\text { of TGF- } \beta 1 \text { in PAD patients. }\end{array}$ & [82] \\
\hline sRAGE & PAD (201) \& healthy controls (201) & Plasma & $\begin{array}{l}\text { Decreased levels of sRAGE in } \\
\text { PAD patients. }\end{array}$ & [83] \\
\hline VEGF & PAD (293) \& healthy controls (26) & Serum & $\begin{array}{l}\text { Higher levels of VEGF in } \\
\text { PAD patients. }\end{array}$ & [84] \\
\hline $\begin{array}{l}\text { Ang2, sTie2, VEGF, } \\
\text { sVEGFR-1 \& PlGF }\end{array}$ & PAD (46) \& healthy controls (23) & Plasma & $\begin{array}{l}\text { Levels of VEGF and sTie2 were } \\
\text { significantly increased in PAD patients. }\end{array}$ & [85] \\
\hline VEGF, PIGF \& TSP-1 & PAD (184) \& healthy controls (330) & Plasma & $\begin{array}{l}\text { Elevated TSP-1 levels associated } \\
\text { with PAD. }\end{array}$ & {$[86]$} \\
\hline $\begin{array}{c}\text { VEGF-A, } \\
\text { TNF- } \alpha \text { \& IL-8 }\end{array}$ & PAD (130) \& controls $(36)$ & Serum & $\begin{array}{l}\text { PAD patients have lower circulating } \\
\text { VEGF-A and higher levels of TNF- } \alpha \\
\text { and IL-8. }\end{array}$ & [71] \\
\hline $\begin{array}{l}\text { EPCs, CD133, } \\
\text { VEGFR-2, } \\
\text { MDA-LDL \& } \\
\text { pentraxin-3 }\end{array}$ & PAD (48) \& healthy controls (22) & $\begin{array}{c}\text { Serum \& } \\
\text { Plasma }\end{array}$ & $\begin{array}{l}\text { EPCs and pentraxin-3 were increased } \\
\text { in PAD patients; Cardiovascular } \\
\text { events in PAD patients were } \\
\text { associated with reduced EPC and } \\
\text { increased MDA-LDL. }\end{array}$ & [87] \\
\hline EPCs & PAD (45) \& healthy controls (24) & Blood & $\begin{array}{l}\text { The number and proliferative activity } \\
\text { of circulating EPCs was significantly } \\
\text { increased in PAD patients. }\end{array}$ & [88] \\
\hline
\end{tabular}

Abbreviations: AIx, Augmentation index; Ang2, Angiopoietin-2; Apwv, Aortic pulse wave velocity; B2M, ß-2-microglobulin; CAD, Coronary artery disease; EPC, Endothelial progenitor cell; HCgp, Human cartilage glycoprotein; hsCRP, high-sensitivity C-reactive protein; ICAM, Intercellular adhesion molecule; IL, Interleukin; Lp-a, Lipoprotein-a; Lp-PLA2, Lipoprotein-associated phospholipase A2; MCP-1, Monocyte chemotactic protein 1; MDA-LDL, Malondialdehyde-modified low-density lipoprotein; MMP, Matrix metalloproteinase; MPO, Myeloperoxidase; NOx, Nitrite/nitrate; NO, Nitric oxide; OxPL/ApoB, Oxidized phospholipids on Apo-B100-containing lipoproteins; PAD, Peripheral artery disease; PlGF, Placenta growth factor; PON-3, Paraoxonase-3; sNOX2-dp, soluble nicotinamide adenine dinucleotide phosphate oxidase 2-derived peptide; sRAGE, Receptor for advanced glycation end products; sTie2, soluble Tyrosine kinase with immunoglobulin-like and EGF-like domains 2; sVEGFR, soluble VEGF receptor; TGF- $\beta$, Transforming growth factor- $\beta$; TNF, Tumour necrosis factor; TNFR2, Tumour necrosis factor receptor 2; TBARS, Thiobarbituric acid-reactive substances; TSP, Thrombospondin; TWEAK, Tumour necrosis factor-like weak inducer of apoptosis; VEGF, Vascular endothelial growth factor. 


\subsubsection{Markers of Athero-Thrombosis and Inflammation}

It was previously reported that a combination of $\beta$-2-microglobulin (B2M), cystatin C, high-sensitivity C-reactive protein (hsCRP) and glucose was associated with PAD [65,66]. Plasma B2M levels and parameters of arterial stiffness such as aortic pulse wave velocity and augmentation index have been reported to be significantly increased in PAD patients [67]. Some studies have shown that combining these circulating markers of inflammation and atherosclerosis with clinical parameters may improve the identification of PAD patients [65,66,71]. A previous nested case-control study reported an increased relative risk of PAD $(2.8,95 \% \mathrm{CI}: 1.3-5.9)$ for subjects in the highest hsCRP quartile compared with the lowest quartile [89].

The levels of a number of lipids and fat related markers have also been reported to be differentially regulated in PAD patients. A recent lipidomic analysis comparing serum lipid profiles in 168 patients with PAD and 161 abdominal aortic aneurysm patients showed that a group of linoleic acid-containing triacylglycerols and diacylglycerols were negatively associated with PAD presence [90]. Furthermore, combining lipidomic features with traditional risk factors significantly improved stratification of patients with PAD and abdominal aortic aneurysm. The levels of total and high molecular weight adiponectin were reported to be significantly lower in women developing PAD [72]. Oxidized phospholipids (OxPL) on Apo-B100-containing lipoproteins (OxPL/ApoB) and the major lipoprotein carrier of OxPL, named lipoprotein-a (Lp-a), have been reported to be positively associated with risk of PAD [73]. Additionally, apolipoprotein (Apo)-A1 and high-density lipoprotein (HDL) have previously been associated with PAD and Apo-AI and homocysteine (Hcy) were reported to be predictors of ABI [91]. It should also be noted that up to $30 \%$ of PAD patients have elevated serum levels of Hcy in comparison to $1 \%$ of the general population [17]. Previous randomised trials have failed to identify any clinical benefit of folic acid and cobalamin supplementation even though this intervention resulted in a reduction in serum Hcy concentration [92]. There are however a number of ongoing clinical trials examining the benefits of such supplementation in PAD patients [92-94]. Patients with asymptomatic PAD have been reported to have a defined profile of pro-inflammatory markers with significantly higher levels of interleukin (IL)-6, E-selectin and matrix metalloproteinase (MMP)-2, MMP-9 and significantly reduced levels of transforming growth factor (TGF)- $\beta 1$ [82].

Recently, a number of novel markers, such as Rho-kinase activity [78] and human cartilage glycoprotein-39 (HCgp-39/YKL-40) [79], have been highlighted as markers of atherosclerosis. The ratio between plasma levels of macrophage scavenger receptor CD163 and tumor necrosis factor-like weak inducer of apoptosis (TWEAK) was also shown to be a potential biomarker of athero-thrombosis in asymptomatic PAD subjects [80]. Since atherosclerosis is a systemic disease, most of these circulating markers may not be specific to PAD but rather reflect the underlying atherosclerotic burden. The paraoxonases (PON) retard lipoprotein oxidation and have been suggested to have anti-atherogenic properties including reducing low density lipoprotein oxidation, reducing oxidative stress, promoting reverse cholesterol transport from macrophages and normalizing vascular endothelial function. PON-1 activity has been suggested to modulate endothelial function in patients with PAD [95]. Circulating levels of PON-3 have been positively associated with B2M, chemokine ligand 2 (CCL2) and hsCRP in CAD, but not in PAD patients [81]. Since atherosclerosis is often widespread, it may be difficult to identify specific markers relating to PAD. Thus, markers that are altered in atherosclerosis in general 
might be of limited clinical application in identifying PAD patients specifically since most of them do not show a unique association with PAD.

\subsubsection{Markers of Oxidative Stress}

An interesting observation was reported recently in relation to gender and racial differences in endothelial oxidative stress in patients with symptomatic PAD [96]. Female African American patients with symptomatic PAD were observed to have increased markers of oxidative stress and elevated levels of circulating pro-inflammatory biomarkers in comparison to males. The women also showed limited peripheral microcirculation, exercise performance, and ambulatory activity compared to male PAD patients. The findings were suggested to support the use of biomarkers related to oxidative stress in identifying symptomatic female PAD patients requiring interventions.

A number of reports suggest that markers of oxidative stress [97-99], such as reactive oxygen species (ROS), are consistently increased in patients with PAD. The bioavailability of ROS within the circulation depends on their rate of formation, by mitochondrial enzymes such as NADPH oxidase (NOX) and xanthine oxidase (XO), and their rate of clearance, through the antioxidant defense system [100]. Furthermore, the bioavailability of NO depends on the balance maintained between the formation of NO and its removal, which is partly dependent on the reaction of NO with ROS. NO is an important component of the complex system that regulates vascular resistance and blood flow distribution [101]. PAD is associated with decreased production of NO [102,103].

Nicotinamide adenine dinucleotide phosphate oxidase (NOX)-2, is a multicomponent enzyme and the catalytic core of NADPH oxidase. NOX-2 mediates electron transfer from NADPH oxidase to molecular oxygen, and is the most important producer of ROS. Compared to controls, patients with PAD have been reported to have enhanced soluble NOX-2-derived peptides, isoprostanes and reduced serum levels of NO and flow mediated dilation [76]. CLI patients have also been reported to have reduced levels of nicotinamide adenine dinucleotide $(\mathrm{NADH})$ and increased levels of NAD+ within their gastrocnemius muscles [104]. These findings suggest that an altered ratio of NAD and NADH within the circulation might reflect a compromised metabolic and redox state in PAD patients. Furthermore, plasma levels of ROS components have been reported to be increased in IC patients [52,77].

\subsubsection{Markers of Vascular Remodeling}

Reduced circulating concentrations of a number of proteins involved in ECM remodeling, such as TGF- $\beta 1$, have been reported in PAD patients [82]. Another protein proposed to be a valuable biomarker of vascular inflammation, as well as PAD presence, is the soluble receptor for advanced glycation end products (sRAGE). It was reported that circulating concentrations of sRAGE were reduced in PAD patients [83]. Serum VEGF has been reported to be positively associated with PAD in one small study, however a larger study assessing plasma VEGF reported no association [71]. Plasma thrombospondin (TSP)-1 has also been reported to be upregulated in PAD patients [86]. Furthermore, TSP-1 has been reported to be expressed in newly formed vessels in PAD patients receiving local injections of bone marrow mononuclear cells and therefore could be reflective of therapeutic angiogenesis. In vitro and in vivo studies have suggested that recombinant human TSP-1 had a negative effect on angiogenesis. siRNA mediated TSP-1 inhibition has been reported to promote endothelial colony forming cells (ECFC) 
proliferation and recombinant human TSP-1 significantly enhanced ECFC adhesion [86]. Furthermore, a short peptide derived from the $N$-terminal part of TSP-1 named TSP-Hep-I also significantly enhanced the adhesion potential of ECFCs. Further work is needed to assess the value of circulating TSP-1 concentrations in identifying and providing prognostic information for PAD patients.

\subsubsection{Circulating Progenitor Cells}

The number of circulating endothelial progenitor cells (EPC) has been reported to be associated with atherosclerosis and CVD however further work is needed to assess its value as a reliable biomarker for PAD [105]. It has, for example, been reported that compared to controls, the number of EPCs and the plasma pentraxin-3 concentration were increased in IC patients, but not in those with CLI [87]. In another study it was reported that cells expressing markers such as CD34 ${ }^{(+)}$or CD133 ${ }^{(+)}$ circulated in lower numbers in PAD patients compared to healthy controls [88]. The cells expressing $\mathrm{CD}_{4}{ }^{(+)}$or $\mathrm{CD} 33^{(+)}$are believed to represent bone marrow progenitors and studies in mice models have suggested they are involved in angiogenesis [80]. A thermal therapy using far infrared rays within a sauna (Waon therapy) has been reported to promote mobilization of CD34 ${ }^{(+)}$cells and augment ischemia induced angiogenesis in mice with hind limb ischemia [106].

Overall, while several biomarkers have been associated with PAD presence currently none of these markers have been consistently demonstrated to improve detection of PAD. In this context, markers of oxidative stress and circulating progenitor cell populations warrant further attention. Further investigations in which markers are examined in large and repeated groups of patients are needed to better examine the potential of using these circulating markers in clinical practice.

\subsection{Markers Associated with the Severity and Outcome of PAD}

Biomarkers may not only be useful in determining the presence or absence of a disease, but could also be useful in predicting patient outcomes. A detailed analysis of a reliable biomarker when combined with established risk factors could assist in stratifying patients at high risk and for selecting optimal treatment. Many published studies have assessed the value of prognostic biomarkers in small groups of patients. However, data that available markers can lead to consistent improvements in clinical management is currently not convincing. It is important that the associations between markers and prognosis observed in smaller isolated studies are followed up by validation in larger cohort studies in independent populations. This section of the review focuses on the most commonly reported circulating biomarkers linked to inflammation, endothelial dysfunction, angiogenesis and vascular remodeling and their relationship with PAD severity and outcomes such as reduced ABI, amputation and mortality (Table 2). 
Table 2. Examples of circulating biomarkers reported to be associated with the severity and outcome of peripheral artery disease.

\begin{tabular}{|c|c|c|c|c|}
\hline Circulating Biomarkers Assessed & Sample Size $(N)$ & $\begin{array}{l}\text { Sample } \\
\text { Studied }\end{array}$ & Association with PAD Severity & Refs. \\
\hline $\begin{array}{l}\text { hsCRP, albumin, } \alpha-2 \text { macroglobulin, } \\
\text { fibrinogen, IL-1 } \beta \text {, IL-1 receptor } \\
\text { antagonist, IL-6, IL- } 6 \text { receptor, IL-10, } \\
\text { IL-18, TNF- } \alpha, \& \text { TGF- } \beta\end{array}$ & InCHIANTI study; PAD (955) & Serum & $\begin{array}{l}\text { Higher levels of IL-1 receptor } \\
\text { antagonist, IL-6, fibrinogen and } \\
\text { hsCRP in PAD patients. }\end{array}$ & [107] \\
\hline hsCRP, DD, TAT III \& vWF & IC (132) \& CLI (30) & Plasma & $\begin{array}{l}\text { Higher levels of hsCRP, vWF, and TAT } \\
\text { III in CLI compared to patients with IC. }\end{array}$ & [108] \\
\hline hsCRP, fibrinogen \& SAA & PAD (91) & Plasma & $\begin{array}{l}\text { hsCRP, fibrinogen, and SAA levels } \\
\text { were significantly associated with CLI; } \\
\text { elevated hsCRP correlated with adverse } \\
\text { graft-related or cardiovascular events. }\end{array}$ & [109] \\
\hline $\begin{array}{c}\text { hsCRP, DD, IL-6, } \\
\text { VCAM-1, ICAM-1 \& Hcy }\end{array}$ & $\begin{array}{l}\text { Walking and Leg Circulation } \\
\text { Study (WALCS); PAD (423) }\end{array}$ & Serum & $\begin{array}{l}\text { Higher levels of inflammation markers } \\
\text { and DD were associated with poorer } \\
\text { lower extremity performance. }\end{array}$ & [110] \\
\hline hsCRP, DD, SAA \& fibrinogen & PAD (337) & Serum & $\begin{array}{l}\text { Elevated baseline levels of } \\
\text { inflammatory markers and DD were } \\
\text { associated with greater decline in the } \\
\text { physical performance. }\end{array}$ & [111] \\
\hline hsCRP & PAD (225) & Plasma & $\begin{array}{l}\text { A risk prediction model including } \\
\text { hsCRP combined with traditional risk } \\
\text { factors, renal function, and nutrition } \\
\text { had excellent discriminatory ability } \\
\text { in predicting all-cause mortality in } \\
\text { patients with clinically advanced } \\
\text { PAD undergoing bypass surgery. }\end{array}$ & [112] \\
\hline hsCRP & PAD (118) & Plasma & $\begin{array}{l}\text { Increased pre-procedural hsCRP } \\
\text { levels were associated with major } \\
\text { adverse limb events and late } \\
\text { cardiovascular events. }\end{array}$ & [113] \\
\hline hsCRP & $\begin{array}{l}\text { Hemodialysis patients } \\
\text { undergoing endovascular } \\
\text { therapy for PAD (234) }\end{array}$ & Serum & $\begin{array}{l}\text { Elevated pre-procedural hsCRP } \\
\text { levels were associated with } \\
\text { re-intervention or above ankle } \\
\text { amputation and any-cause death after } \\
\text { endovascular therapy. }\end{array}$ & [114] \\
\hline hsCRP & $\begin{array}{c}\text { European Prospective } \\
\text { Investigation into Cancer and } \\
\text { Nutrition (EPIC)-Norfolk cohort; } \\
\text { Healthy participants }(18,450)\end{array}$ & Serum & $\begin{array}{l}\text { In the EPIC-Norfolk cohort, hsCRP was } \\
\text { associated with nonfatal PAD events. }\end{array}$ & [115] \\
\hline hsCRP, LDL \& HDL & Total PAD (100); IC (73) & Blood & $\begin{array}{l}\text { Walking disability in PAD was } \\
\text { associated with arterial endothelial } \\
\text { dysfunction; Endothelial dysfunction } \\
\text { was more significantly associated } \\
\text { with walking disability in IC. }\end{array}$ & [116] \\
\hline
\end{tabular}


Table 2. Cont.

\begin{tabular}{|c|c|c|c|c|}
\hline Circulating Biomarkers Assessed & Sample Size $(N)$ & $\begin{array}{l}\text { Sample } \\
\text { Studied }\end{array}$ & Association with PAD Severity & Refs. \\
\hline $\begin{array}{l}\text { ApoA-I, HDL, Hcy, } \\
\text { folate \& vitamin B12 }\end{array}$ & $\begin{array}{c}\text { Elderly volunteers from } \\
\text { rural Sicily (667) }\end{array}$ & Serum & $\begin{array}{l}\text { Decreased ApoA-I and increased } \\
\text { Hcy were predictors of ABI. }\end{array}$ & [91] \\
\hline VCAM-1, ICAM-1 \& MCP-1 & PAD (112) & Serum & $\begin{array}{l}\text { Increased sVCAM-1 and sICAM-1 } \\
\text { were associated with PAD. }\end{array}$ & [117] \\
\hline ICAM-1, leptin, Apolipoprotein-CIII & PAD (148) & Serum & $\begin{array}{l}\text { African American women with } \\
\text { symptomatic PAD had an increased } \\
\text { oxidative stress related markers } \\
\text { compared with men. }\end{array}$ & {$[96]$} \\
\hline MPO & PAD (406) & Plasma & $\begin{array}{l}\text { Plasma level was useful for risk } \\
\text { stratification of PAD. }\end{array}$ & [118] \\
\hline $\begin{array}{l}\text { TRAP-6-inducible } \\
\text { P-selectin expression }\end{array}$ & PAD (108) & Blood & $\begin{array}{l}\text { Low thrombin generation potential } \\
\text { was associated with an } 11.7 \text {-fold } \\
\text { increased risk of future } \\
\text { atherothrombotic events. }\end{array}$ & [119] \\
\hline Galectin-3 & CLI (55) & Serum & Increased levels of Galectin-3 in CLI. & [120] \\
\hline NT-pro-BNP & $\begin{array}{l}\text { PCA (100), PAD (300) \& } \\
\text { healthy controls (300) }\end{array}$ & Serum & $\begin{array}{l}\text { Patients with PCA had higher levels } \\
\text { of NT pro-BNP than PAD and } \\
\text { controls suggestive of an adverse } \\
\text { hemodynamic milieu and } \\
\text { increased risk for adverse } \\
\text { cardiovascular outcomes. }\end{array}$ & [121] \\
\hline NT-pro-BNP & PAD (481) & Serum & $\begin{array}{l}\text { Higher levels of NT-pro-BNP were } \\
\text { independently associated with a } \\
\text { lower ordinal walking category or } \\
\text { functional capacity. }\end{array}$ & [122] \\
\hline $\begin{array}{l}\text { Ang2, Tie2, VEGF, } \\
\text { VEGFR-1 \& PIGF }\end{array}$ & PAD (46) \& healthy controls (23) & Plasma & $\begin{array}{l}\text { Levels of VEGF and sTie } 2 \text { were } \\
\text { significantly increased in CLI. }\end{array}$ & {$[85]$} \\
\hline VEGF-A $165 b$ & PAD (18) & Serum & $\begin{array}{l}\text { Increased anti-angiogenic } \\
\text { VEGF-165b and a corresponding } \\
\text { reduction in levels of the } \\
\text { pro-angiogenic VEGF-A165a. }\end{array}$ & [123] \\
\hline
\end{tabular}

Abbreviations: ALI, Acute limb ischemia; Ang2, Angiopoietin-2; CLI, Critical limb ischemia; DD, D-Dimer; Hcy, Homocysteine; HDL, High-density lipoprotein; hsCRP, high-sensitivity C-reactive protein; IC, Intermittent claudication; ICAM, Intercellular adhesion molecule; IL, Interleukin; LDL, Low-density lipoprotein; MCP-1, Monocyte chemotactic protein 1; MPO, Myeloperoxidase; MMP, Matrix metalloproteinase; NO, Nitric oxide; NT-pro-BNP, $N$-terminal pro-B-type natriuretic peptide; PAD, Peripheral artery disease; PCA, Poorly compressible arteries; P1GF, Placenta growth factor; SAA, serum amyloid A; TAT III, Thrombin-antithrombin III; TGF- $\beta$, Transforming growth factor- $\beta$; TIMP, Tissue inhibitor of matrix metalloprotenase; TNF, Tumour necrosis factor; VCAM, Vascular adhesion molecule; VEGF, Vascular endothelial growth factor; vWF, von Willebrand factor. 


\subsubsection{Markers of Inflammation}

Multiple studies have reported that inflammation associated biomarkers circulate at higher levels in PAD patients with more severe disease [68,70,107-109,124] (Table 2). Cholesterol undergoes oxidation via both enzymatic stress-driven and free radical-mediated mechanisms and generates a range of oxysterols. Accumulation of hydroxycholesterols (HC) such as 25-HC, 27-HC and 24S-HC in the aortic intima was associated with systemic inflammatory activity and advanced atherosclerotic disease in individuals with severe PAD [125]. In the National Health and Nutrition Examination Survey of American men and women aged $\geq 40$ years $(n=4787)$, elevated levels of hsCRP, fibrinogen, and leukocyte counts were associated with lower ABI values [68]. High levels of the inflammatory markers IL-6, hsCRP, soluble vascular adhesion molecule-1 (sVCAM-1) and soluble intercellular adhesion molecule-1 (sICAM-1) have been reported to be associated with accelerated functional decline in PAD patients $[69,82,110,111,117]$ and with PAD complications such as amputation or general complications such as MI, stroke and death (Table 2). A risk prediction model was developed in a prospective cohort study of patients with clinically advanced PAD undergoing lower extremity bypass surgery $(n=225$, followed up for a median of 893 days). The study showed that the traditional risk factors and circulating markers of inflammation such as hsCRP, sVCAM-1, renal function, and nutrition had excellent discriminatory ability in predicting all-cause mortality in PAD patients [112]. hsCRP has been shown to be an independent predictor of adverse cardiovascular outcomes and increased risk of secondary interventions or limb loss in PAD patients [126]. Elevated pre-procedural serum levels of hsCRP have been associated with requirement for re-intervention or above ankle amputation and mortality after endovascular therapy in haemodialysis patients with PAD [114]. Similar findings have been reported in other PAD patient groups [113]. A recent large prospective cohort study involving 18,450 participants (European Prospective Investigation into Cancer and Nutrition (EPIC) - Norfolk cohort) reported a strong and independent association between elevated hsCRP levels and an increased risk of PAD complications [115].

\subsubsection{Markers of Oxidative Stress and Endothelial Damage}

Myeloperoxidase (MPO) is a peroxidase enzyme stored in neutrophils and a key mediator of inflammatory and redox-dependent processes in atherosclerosis. MPO has been reported to promote atherosclerosis via inducing oxidative stress in animal models [127,128]. A previous study suggested the potential value of using plasma MPO for risk stratification of major adverse events in PAD patients [118]. Similarly, in vitro thrombin generation potential was reported to correlate inversely with protease-activated receptors (PAR)-1-mediated platelet activation and was linked to the occurrence of athero-thrombotic events in patients with PAD [119]. The protein Galectin-3 is a soluble $\beta$-galactoside-binding lectin protein that has been implicated in athero-thrombosis and suggested as a biomarker for heart failure [129]. A five-year follow-up study of 309 PAD patients reported that circulating Galectin-3 concentrations were significantly and independently associated with an increased risk for CVD mortality $(\mathrm{OR}=2.24,95 \% \mathrm{CI}: 1.06-4.73 ; p<0.05)$ suggesting its potential use as a prognostic marker [130]. 
Arterial occlusion results in inadequate oxygen supply to the lower extremities and concurrent defective clearance of toxic metabolites. The net result is the accumulation of ROS, leading to tissue necrosis and microcirculatory damage that eventually result in irreversible deterioration and injury to the endothelial lining [131,132]. A previous study reported that reduced walking ability in PAD patients was associated with arterial endothelial dysfunction [116]. In another study however circulating concentrations of the endothelial marker NO were not associated with the severity of PAD [69]. Plasma levels of ROS markers, such as thiobarbituric acid-reactive substances (TBARS), sICAM-1 and antioxidants were increased in IC patients indicating that increased ROS production and damaged electron transport chain complexes may contribute to PAD and may serve as potential markers for its severity [52,77,133].

A recent report suggests that serum $N$-terminal pro-B-type natriuretic peptide (NT-pro-BNP) levels are associated with functional capacity in patients with PAD and may be a marker of hemodynamic stress in these patients [122]. Natriuretic peptides are mainly secreted from the heart in response to increased wall stress and NT-pro-BNP is elevated in patients with increased left ventricular mass and coronary heart disease, in addition to PAD [134]. Higher levels of circulating NT-pro-BNP have been associated with increased CVD mortality in PAD patients [113], and also patients with CHD [135,136]. Serum NT-pro-BNP levels were reported to be significantly higher in patients with poorly compressible arteries (PCA) than in those with PAD [121]. PCA occur due to medial arterial calcification and patients with PCA have an elevated ABI. Medial arterial calcification is associated with a number of chronic disease conditions and an increased risk predictor for CVD events and lower extremity amputation [137]. Even though medial arterial calcification and intimal calcification (which is a hallmark of atherosclerosis) may coexist, these two conditions are suggested to be distinct [138]. A recent report on the histopathological assessment of PAD (176 upper and lower leg artery specimens) patients highlights that the most common observations were medial calcification (present in $72 \%$ of arteries examined) and intimal thickening without lipid (present in $68 \%$ of arteries examined). Classical atherosclerosis was only identified in $23 \%$ of arteries [139]. Non-atheromatous intimal thickening was frequently observed, resulting in complete occlusion in some vessels. This suggests that vascular lesions in PAD patients may have additional pathological mechanisms other than atherosclerosis alone.

\subsubsection{Markers of Vascular Remodeling}

One of the most studied markers of angiogenesis in PAD is VEGF and its receptors R1 and R2. VEGF-R1 is characteristically up-regulated by hypoxia and its soluble form has been proposed as a marker for CLI. Patients with advanced PAD have been reported to have elevated serum and tissue levels of VEGF compared to age matched healthy volunteers [84,85]. Furthermore, VEGF values in Fontaine class IV patients have been reported to be almost double that in healthy controls. High circulating VEGF levels have been associated with poor outcomes, such as major amputation, suggesting serum VEGF to be a potential marker for PAD severity. These findings could be interpreted as suggesting that administration of VEGF in an attempt to achieve therapeutic angiogenesis for CLI may not be safe [140]. It is however likely that the association of high VEGF concentrations with poor outcome reflects reverse causality as a response to the severity of ischemia rather than a cause. 
Another, member of the VEGF family is VEGF-A, which exists as several isoforms produced as a result of alternative splicing. Reduced levels of circulating levels of total VEGF-A have been observed in IC patients compared to healthy controls [71]. Lower levels of total VEGF-A have also been associated with a reduction in capillary to muscle fibre ratio in PAD subjects [141]. A recent report suggested that in PAD, vascular insufficiency occurs in spite of elevated levels of total VEGF-A [123]. However, further analysis showed that PAD was associated with elevated levels of a VEGF-A splice isoform, VEGF-A165b and a corresponding reduction in levels of the VEGF-A165a splice isoform. Further studies in a rodent model suggested that VEGFA-165b had anti-angiogenic properties and the VEGF-A165a isoform was pro-angiogenic. Studies in a mouse model of PAD suggested that administration of VEGF-A165b inhibited revascularization [123]. Additional studies are warranted in patients in different PAD stages to understand the use of various VEGF-A isoforms as markers of angiogenesis status. Higher levels of plasma angiopoietin-2 (Ang2), and soluble Tie2 (sTie2) have been reported in patients with CLI compared to those with IC [85], indicating that there are other potential circulating biomarkers of disease severity that warrant attention.

The ECM plays a major role in regulating angiogenesis and in vitro and in vivo studies suggest a crucial role of proteolytic enzymes and matrix proteins in creating a permissive microenvironment to promote blood vessel sprouting [142-144]. Reorganization of the ECM, promoted by MMPs, creates space required for expansive remodeling of the pre-existing collaterals. Circulating levels of MMP-2, MMP-9, MMP-19 and Tissue inhibitor of metalloproteinase (TIMP)-1 have been reported to be elevated in CLI patients [74,82,145]. Furthermore, elevated plasma levels of MMP-2 and MMP-9 have been associated with PAD severity [146]. A previous study reported that the levels of both MMP-2 and MMP-9 (both the latent and the active forms) significantly increased during the active phase of limb reperfusion [147]. This temporal increase in MMP activity coincided with enhanced exposure of the unique cryptic collagen epitope (HU177) which has been previously implicated in angiogenesis in ischemic muscle. These findings suggest an important role for collagen remodeling during the active phase of ischemic limb reperfusion. Furthermore, studies in an animal model suggest that MMP-9 is essential for ischemia induced neovascularization by modulating bone marrow derived EPCs. MMP-9 deficiency impairs ischemia-induced neovascularization, through a reduction in EPC mobilization, migration, and vasculogenesis functions [148]. Additionally, use of ischemic muscle markers is only likely to be practical clinically if circulating forms of these markers are reflective of those in the muscle. It is not currently clear whether any reliable relationship exists between blood and muscle marker levels.

\section{Conclusions}

In this review, we have presented an overview of markers associated with PAD presence and outcome. A number of limitations exist for circulating markers currently identified. There is little consensus on which markers are consistently associated with PAD and there are definite challenges in identifying markers that are PAD-specific. The circulating markers should ideally reflect the changes occurring in the ischemic lower-limb muscles. In order to have clinical utility, the circulating biomarkers should predict risk independently of other established PAD risk factors. Furthermore, the circulating marker should be specific and sensitive and easily assayed. 
Biomarkers that could effectively predict PAD development, progression and outcome could be extremely useful in the clinical setting [149-151]. Ideally such markers would also identify patients best suited to different types of treatment. Currently, however, there is no convincing evidence that the markers investigated are reliable and specific. Even though novel markers such as Rho-kinase activity, human cartilage glycoprotein-39, TWEAK and PON-3, have been associated with PAD presence, their validity as reliable marker is unclear as these individual reports are frequently not followed by other replication studies. Some markers of inflammation, such as B2M, hsCRP and interleukins, oxidative stress, such as NO and NOX-2, ECM remodeling, such as TGF- $\beta 1$, TSP-1 and VEGF, and circulating progenitor cell populations have been consistently associated with PAD presence (Figure 2). Similarly, markers of inflammation, such as hsCRP and sVCAM-1, oxidative stress, such as MPO and NT-pro-BNP, ECM remodeling, such as VEGF, VEGF-A isoforms and MMPs, have been consistently associated with PAD severity. Since cell therapy is a promising approach in PAD management, assessment of circulating stem cell populations may be of potential value. A comprehensive characterization of the circulating progenitor cell markers may be useful in identifying patients suitable for cell therapies. It should also be noted that initial investigations often over-estimates the effect size of a discovered association and thus it is important to re-assess findings in different populations. Thus it is important that prospective studies using large patient populations are conducted to validate biomarkers of interest to gain insight into their "real-world" benefit as diagnostic or prognostic aids.

In summary: (1) PAD is multifactorial; therefore single biomarker may not be powerful enough for reliable diagnosis and/or prognosis. Rather a combination of risk factor and circulating marker data may be needed; (2) Identifying a marker specific to PAD rather than general athero-thrombosis may be technically challenging; (3) Despite considerable effort, no biomarkers have been currently shown as sufficiently robust to be incorporated into clinical practice. Even though a number of currently identified circulating markers show promise, further larger studies focused on the clinical value of such markers over existing risk predictors are needed. 


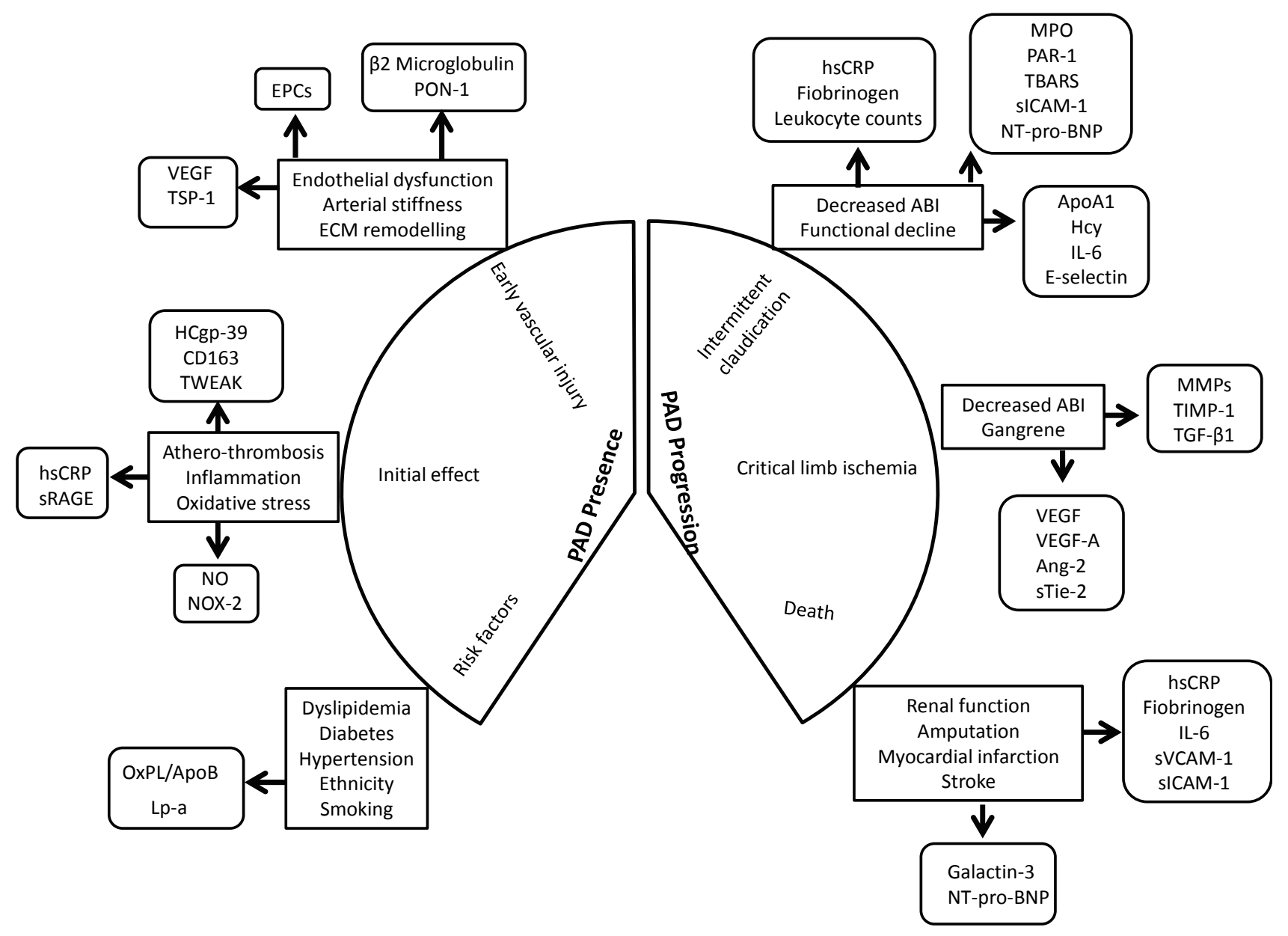

Figure 2. Circulating biomarkers in peripheral artery disease. A schematic depiction of the stages at which circulating biomarkers could be informative in the peripheral artery disease (PAD) course. Since PAD is multifactorial it is likely that a single biomarker may not be sufficient to predict diagnosis or prognosis. Since PAD development and progression is due to the interaction of multiple factors, it is possible that the combination of a number of biomarkers may be preferable to a single maker. Abbreviations: ABI, Ankle brachial index; Ang-2, Angiopoetin-2; ApoA1, Apolipoprotein A1; B2M, $\beta$-2-microglobulin; EPC, Endothelial progenitor cell; HCgp, Human cartilage glycoprotein; Hcy, Homocysteine; hsCRP, high sensitivity C-reactive protein; IL, Interleukin; Lp-a, Lipoprotein-1; MMP, Matrix mettalloprotenase; MPO, Myeloperoxidase; NO, Nitric oxide; NOX, NADPH Oxidase; NT-pro-BNP, $N$-terminal pro-B-type natriuretic peptide; OxPL/ApoB, Oxidised phospholipids on ApoB100 containing lipoproteins; PAD, Peripheral artery disease; PAR, Protease activated receptor; PON, Paraoxonase; sICAM-1, soluble Intercellular adhesion molecule-1; sRAGE, soluble receptor for advanced glycation end product; sTie-2, soluble Tyrosine kinase with immunoglobulin-like and EGF-like domains 2; sVCAM-1, soluble Vascular cell adhesion molecule-1; TBARS, Thiobarbituric acid-reactive substrates; TGF, Transforming growth factor; TWEAK, Tumour necrosis factor like weak inducer of apoptosis; TSP, Thrombospondin; TIMP, Tissue inhibitor of matrix metalloproteinase; VEGF, Vascular endothelial growth factor. 


\section{Acknowledgments}

This work was funded in part by grants from the National Health and Medical Research Council (1063476, 1021416, 1003707 and 1000967), the Queensland Government and the Townsville Hospital Private Practice Trust. Jonathan Golledge holds a Practitioner Fellowship from the National Health and Medical Research Council, Australia (1019921) and a Senior Clinical Research Fellowship from the Queensland Government. This work was also funded by a Faculty Grant Scheme, College of Medicine and Dentistry, James Cook University. The funding bodies played no role in generation of the data presented in this publication.

\section{Author Contributions}

Smriti Murali Krishna designed the review, was responsible for figure and table preparation, screened the literature, and wrote the manuscript. Joseph. V. Moxon contributed to manuscript preparation and revised the manuscript. Jonathan Golledge critically revised the manuscript.

\section{Conflicts of Interest}

The authors declare no conflict of interest.

\section{References}

1. Knowles, J.W.; Assimes, T.L.; Li, J.; Quertermous, T.; Cooke, J.P. Genetic susceptibility to peripheral arterial disease: A dark corner in vascular biology. Arterioscler. Thromb. Vasc. Biol. 2007, 27, 2068-2078.

2. Subherwal, S.; Patel, M.R.; Kober, L.; Peterson, E.D.; Bhatt, D.L.; Gislason, G.H.; Olsen, A.M.; Jones, W.S.; Torp-Pedersen, C.; Fosbol, E.L. Peripheral artery disease is a coronary heart disease risk equivalent among both men and women: Results from a nationwide study. Eur. J. Prev. Cardiol. 2015, 22, 317-325.

3. Walker, T.G. Acute limb ischemia. Tech. Vasc. Interv. Radiol. 2009, 12, 117-129.

4. Norman, P.E.; Eikelboom, J.W.; Hankey, G.J. Peripheral arterial disease: Prognostic significance and prevention of atherothrombotic complications. Med. J. Aust. 2004, 181, 150-154.

5. Bergiers, S.; Vaes, B.; Degryse, J. To screen or not to screen for peripheral arterial disease in subjects aged 80 and over in primary health care: A cross-sectional analysis from the belfrail study. BMC Family Pract. 2011, 12, 39.

6. Hirsch, A.T.; Criqui, M.H.; Treat-Jacobson, D.; Regensteiner, J.G.; Creager, M.A.; Olin, J.W.; Krook, S.H.; Hunninghake, D.B.; Comerota, A.J.; Walsh, M.E.; et al. Peripheral arterial disease detection, awareness, and treatment in primary care. JAMA 2001, 286, 1317-1324.

7. Allison, M.A.; Ho, E.; Denenberg, J.O.; Langer, R.D.; Newman, A.B.; Fabsitz, R.R.; Criqui, M.H. Ethnic-specific prevalence of peripheral arterial disease in the united states. Am. J. Prev. Med. 2007, 32, 328-333.

8. Selvin, E.; Erlinger, T.P. Prevalence of and risk factors for peripheral arterial disease in the united states: Results from the national health and nutrition examination survey, 1999-2000. Circulation 2004, 110, 738-743. 
9. Dohmen, A.; Eder, S.; Euringer, W.; Zeller, T.; Beyersdorf, F. Chronic critical limb ischemia. Dtsch. Arztebl. Int. 2012, 109, 95-101.

10. Norgren, L.; Hiatt, W.R.; Dormandy, J.A.; Nehler, M.R.; Harris, K.A.; Fowkes, F.G.; Bell, K.; Caporusso, J.; Durand-Zaleski, I.; Komori, K.; et al. Inter-society consensus for the management of peripheral arterial disease (TASC II). Eur. J. Vasc. Endovasc. Surg. 2007, 33 (Suppl. S1), S1-S75.

11. Fowkes, F.G.; Rudan, D.; Rudan, I.; Aboyans, V.; Denenberg, J.O.; McDermott, M.M.; Norman, P.E.; Sampson, U.K.; Williams, L.J.; Mensah, G.A.; et al. Comparison of global estimates of prevalence and risk factors for peripheral artery disease in 2000 and 2010: A systematic review and analysis. Lancet 2013, 382, 1329-1340.

12. Society for Vascular Surgery Lower Extremity Guidelines Writing Group; Conte, M.S.; Pomposelli, F.B.; Clair, D.G.; Geraghty, P.J.; McKinsey, J.F.; Mills, J.L.; Moneta, G.L.; Murad, M.H.; Powell, R.J.; et al. Society for vascular surgery practice guidelines for atherosclerotic occlusive disease of the lower extremities: Management of asymptomatic disease and claudication. J. Vasc. Surg. 2015, 61, S2-S41.

13. Hirsch, A.T.; Hartman, L.; Town, R.J.; Virnig, B.A. National health care costs of peripheral arterial disease in the medicare population. Vasc. Med. 2008, 13, 209-215.

14. Adam, D.J.; Beard, J.D.; Cleveland, T.; Bell, J.; Bradbury, A.W.; Forbes, J.F.; Fowkes, F.G.; Gillepsie, I.; Ruckley, C.V.; Raab, G.; et al. Bypass versus angioplasty in severe ischaemia of the leg (basil): Multicentre, randomised controlled trial. Lancet 2005, 366, 1925-1934.

15. Lawall, H.; Bramlage, P.; Amann, B. Treatment of peripheral arterial disease using stem and progenitor cell therapy. J. Vasc. Surg. 2011, 53, 445-453.

16. Hirsch, A.T.; Haskal, Z.J.; Hertzer, N.R.; Bakal, C.W.; Creager, M.A.; Halperin, J.L.; Hiratzka, L.F.; Murphy, W.R.; Olin, J.W.; Puschett, J.B.; et al. Acc/aha 2005 practice guidelines for the management of patients with peripheral arterial disease (lower extremity, renal, mesenteric, and abdominal aortic): A collaborative report from the american association for vascular surgery/society for vascular surgery, society for cardiovascular angiography and interventions, society for vascular medicine and biology, society of interventional radiology, and the acc/aha task force on practice guidelines (writing committee to develop guidelines for the management of patients with peripheral arterial disease): Endorsed by the american association of cardiovascular and pulmonary rehabilitation; national heart, lung, and blood institute; society for vascular nursing; transatlantic inter-society consensus; and vascular disease foundation. Circulation 2006, 113, e463-e654.

17. Norgren, L.; Hiatt, W.R.; Dormandy, J.A.; Nehler, M.R.; Harris, K.A.; Fowkes, F.G.; TASC II Working Group. Inter-society consensus for the management of peripheral arterial disease (TASC II). J. Vasc. Surg. 2007, 45, S5-S67.

18. Varu, V.N.; Hogg, M.E.; Kibbe, M.R. Critical limb ischemia. J. Vasc. Surg. 2010, 51, 230-241.

19. Lau, J.F.; Weinberg, M.D.; Olin, J.W. Peripheral artery disease. Part 1: Clinical evaluation and noninvasive diagnosis. Nat. Rev. Cardiol. 2011, 8, 405-418.

20. Cheshire, N.J.; Wolfe, J.H.; Noone, M.A.; Davies, L.; Drummond, M. The economics of femorocrural reconstruction for critical leg ischemia with and without autologous vein. J. Vasc. Surg. 1992, 15, 167-174; discussion 174-165. 
21. Albers, M.; Fratezi, A.C.; de Luccia, N. Assessment of quality of life of patients with severe ischemia as a result of infrainguinal arterial occlusive disease. J. Vasc. Surg. 1992, 16, 54-59.

22. Schuler, J.J.; Flanigan, D.P.; Holcroft, J.W.; Ursprung, J.J.; Mohrland, J.S.; Pyke, J. Efficacy of prostaglandin E1 in the treatment of lower extremity ischemic ulcers secondary to peripheral vascular occlusive disease. Results of a prospective randomized, double-blind, multicenter clinical trial. J. Vasc. Surg. 1984, 1, 160-170.

23. Santilli, J.D.; Santilli, S.M. Chronic critical limb ischemia: Diagnosis, treatment and prognosis. Am. Fam. Physician 1999, 59, 1899-1908.

24. Arnold, T.E.; Kerstein, M.D. Secondary distal extension of infrainguinal bypass: Long-term limb and patient survival. Ann. Vasc. Surg. 2000, 14, 450-456.

25. Brumberg, R.S.; Back, M.R.; Armstrong, P.A.; Cuthbertson, D.; Shames, M.L.; Johnson, B.L.; Bandyk, D.F. The relative importance of graft surveillance and warfarin therapy in infrainguinal prosthetic bypass failure. J. Vasc. Surg. 2007, 46, 1160-1166.

26. Davies, M.G. Critical limb ischemia: Cell and molecular therapies for limb salvage. Methodist DeBakey Cardiovasc. J. 2012, 8, 20-27.

27. Sigvant, B.; Wiberg-Hedman, K.; Bergqvist, D.; Rolandsson, O.; Andersson, B.; Persson, E.; Wahlberg, E. A population-based study of peripheral arterial disease prevalence with special focus on critical limb ischemia and sex differences. J. Vasc. Surg. 2007, 45, 1185-1191.

28. Peacock, J.M.; Keo, H.H.; Duval, S.; Baumgartner, I.; Oldenburg, N.C.; Jaff, M.R.; Henry, T.D.; $\mathrm{Yu}, \mathrm{X}$.; Hirsch, A.T. The incidence and health economic burden of ischemic amputation in minnesota, 2005-2008. Prev. Chronic Dis. 2011, 8, A141.

29. Meijer, W.T.; Grobbee, D.E.; Hunink, M.G.; Hofman, A.; Hoes, A.W. Determinants of peripheral arterial disease in the elderly: The rotterdam study. Arch. Intern. Med. 2000, 160, 2934-2938.

30. Selvin, E.; Marinopoulos, S.; Berkenblit, G.; Rami, T.; Brancati, F.L.; Powe, N.R.; Golden, S.H. Meta-analysis: Glycosylated hemoglobin and cardiovascular disease in diabetes mellitus. Ann. Intern. Med. 2004, 141, 421-431.

31. Muntner, P.; Wildman, R.P.; Reynolds, K.; Desalvo, K.B.; Chen, J.; Fonseca, V. Relationship between HbA1c level and peripheral arterial disease. Diabetes Care 2005, 28, 1981-1987.

32. Lo, R.C.; Bensley, R.P.; Dahlberg, S.E.; Matyal, R.; Hamdan, A.D.; Wyers, M.; Chaikof, E.L.; Schermerhorn, M.L. Presentation, treatment, and outcome differences between men and women undergoing revascularization or amputation for lower extremity peripheral arterial disease. J. Vasc. Surg. 2014, 59, 409-418.

33. McGinigle, K.L.; Kalbaugh, C.A.; Marston, W.A. Living in a medically underserved county is an independent risk factor for major limb amputation. J. Vasc. Surg. 2014, 59, 737-741.

34. Fadini, G.P.; Agostini, C.; Avogaro, A. Autologous stem cell therapy for peripheral arterial disease meta-analysis and systematic review of the literature. Atherosclerosis 2010, 209, 10-17.

35. Lawall, H.; Bramlage, P.; Amann, B. Stem cell and progenitor cell therapy in peripheral artery disease. A critical appraisal. Thromb. Haemost. 2010, 103, 696-709.

36. Morris, D.R.; Rodriguez, A.J.; Moxon, J.V.; Cunningham, M.A.; McDermott, M.M.; Myers, J.; Leeper, N.J.; Jones, R.E.; Golledge, J. Association of lower extremity performance with cardiovascular and all-cause mortality in patients with peripheral artery disease: A systematic review and meta-analysis. J. Am. Heart Assoc. 2014, 3, doi:10.1161/JAHA.114.001105. 
37. Aranguren, X.L.; Verfaillie, C.M.; Luttun, A. Emerging hurdles in stem cell therapy for peripheral vascular disease. J. Mol. Med. 2009, 87, 3-16.

38. Jones, W.S.; Dolor, R.J.; Hasselblad, V.; Vemulapalli, S.; Subherwal, S.; Schmit, K.; Heidenfelder, B.; Patel, M.R. Comparative effectiveness of endovascular and surgical revascularization for patients with peripheral artery disease and critical limb ischemia: Systematic review of revascularization in critical limb ischemia. Am. Heart. J. 2014, 167, 489-498.

39. Gupta, R.; Tongers, J.; Losordo, D.W. Human studies of angiogenic gene therapy. Circ. Res. 2009, 105, 724-736.

40. De Haro, J.; Acin, F.; Lopez-Quintana, A.; Florez, A.; Martinez-Aguilar, E.; Varela, C. Meta-analysis of randomized, controlled clinical trials in angiogenesis: Gene and cell therapy in peripheral arterial disease. Heart Vessels 2009, 24, 321-328.

41. Matoba, S.; Tatsumi, T.; Murohara, T.; Imaizumi, T.; Katsuda, Y.; Ito, M.; Saito, Y.; Uemura, S.; Suzuki, H.; Fukumoto, S.; et al. Long-term clinical outcome after intramuscular implantation of bone marrow mononuclear cells (therapeutic angiogenesis by cell transplantation (TACT) trial) in patients with chronic limb ischemia. Am. Heart. J. 2008, 156, 1010-1018.

42. Powell, R.J.; Marston, W.A.; Berceli, S.A.; Guzman, R.; Henry, T.D.; Longcore, A.T.; Stern, T.P.; Watling, S.; Bartel, R.L. Cellular therapy with ixmyelocel-T to treat critical limb ischemia: The randomized, double-blind, placebo-controlled RESTORE-CLI trial. Mol. Ther. J. Am. Soc. Gene Ther. 2012, 20, 1280-1286.

43. Coats, P.; Wadsworth, R. Marriage of resistance and conduit arteries breeds critical limb ischemia. Am. J. Physiol. Heart Circ. Physiol. 2005, 288, H1044-H1050.

44. Scholz, D.; Ziegelhoeffer, T.; Helisch, A.; Wagner, S.; Friedrich, C.; Podzuweit, T.; Schaper, W. Contribution of arteriogenesis and angiogenesis to postocclusive hindlimb perfusion in mice. J. Mol. Cell. Cardiol. 2002, 34, 775-787.

45. Kuang, S.; Gillespie, M.A.; Rudnicki, M.A. Niche regulation of muscle satellite cell self-renewal and differentiation. Cell Stem Cell 2008, 2, 22-31.

46. Badimon, L.; Vilahur, G. Thrombosis formation on atherosclerotic lesions and plaque rupture. J. Intern. Med. 2014, 276, 618-632.

47. Popovic, M.; Smiljanic, K.; Dobutovic, B.; Syrovets, T.; Simmet, T.; Isenovic, E.R. Thrombin and vascular inflammation. Mol. Cell. Biochem. 2012, 359, 301-313.

48. Lippi, G.; Franchini, M.; Targher, G. Arterial thrombus formation in cardiovascular disease. Nat. Rev. Cardiol. 2011, 8, 502-512.

49. Koutakis, P.; Myers, S.A.; Cluff, K.; Ha, D.M.; Haynatzki, G.; McComb, R.D.; Uchida, K.; Miserlis, D.; Papoutsi, E.; Johanning, J.M.; et al. Abnormal myofiber morphology and limb dysfunction in claudication. J. Surg. Res. 2015, doi:10.1016/j.jss.2015.02.011.

50. Pipinos, I.I.; Judge, A.R.; Selsby, J.T.; Zhu, Z.; Swanson, S.A.; Nella, A.A.; Dodd, S.L. The myopathy of peripheral arterial occlusive disease: Part 1. Functional and histomorphological changes and evidence for mitochondrial dysfunction. Vasc. Endovasc. Surg. 2007, 41, 481-489.

51. Pipinos, I.I.; Judge, A.R.; Selsby, J.T.; Zhu, Z.; Swanson, S.A.; Nella, A.A.; Dodd, S.L. The myopathy of peripheral arterial occlusive disease: Part 2. Oxidative stress, neuropathy, and shift in muscle fiber type. Vasc. Endovasc. Surg. 2008, 42, 101-112. 
52. Hickman, P.; Harrison, D.K.; Hill, A.; McLaren, M.; Tamei, H.; McCollum, P.T.; Belch, J.J. Exercise in patients with intermittent claudication results in the generation of oxygen derived free radicals and endothelial damage. Adv. Exp. Med. Biol. 1994, 361, 565-570.

53. Bhat, H.K.; Hiatt, W.R.; Hoppel, C.L.; Brass, E.P. Skeletal muscle mitochondrial DNA injury in patients with unilateral peripheral arterial disease. Circulation 1999, 99, 807-812.

54. Scholz, D.; Cai, W.J.; Schaper, W. Arteriogenesis, a new concept of vascular adaptation in occlusive disease. Angiogenesis 2001, 4, 247-257.

55. Pipp, F.; Boehm, S.; Cai, W.J.; Adili, F.; Ziegler, B.; Karanovic, G.; Ritter, R.; Balzer, J.; Scheler, C.; Schaper, W.; et al. Elevated fluid shear stress enhances postocclusive collateral artery growth and gene expression in the pig hind limb. Arterioscler. Thromb. Vasc. Biol. 2004, 24, 1664-1668.

56. Tronc, F.; Wassef, M.; Esposito, B.; Henrion, D.; Glagov, S.; Tedgui, A. Role of no in flow-induced remodeling of the rabbit common carotid artery. Arterioscler. Thromb. Vasc. Biol. 1996, 16, 1256-1262.

57. Tronc, F.; Mallat, Z.; Lehoux, S.; Wassef, M.; Esposito, B.; Tedgui, A. Role of matrix metalloproteinases in blood flow-induced arterial enlargement: Interaction with no. Arterioscler. Thromb. Vasc. Biol. 2000, 20, E120-E126.

58. Dragneva, G.; Korpisalo, P.; Yla-Herttuala, S. Promoting blood vessel growth in ischemic diseases: Challenges in translating preclinical potential into clinical success. Dis. Model. Mech. 2013, 6, 312-322.

59. Shimamura, M.; Nakagami, H.; Taniyama, Y.; Morishita, R. Gene therapy for peripheral arterial disease. Expert Opin. Biol. Ther. 2014, 14, 1175-1184.

60. Shimamura, M.; Nakagami, H.; Koriyama, H.; Morishita, R. Gene therapy and cell-based therapies for therapeutic angiogenesis in peripheral artery disease. Biol. Med. Res. Int. 2013, $2013,186215$.

61. Henry, T.D.; Hirsch, A.T.; Goldman, J.; Wang, Y.L.; Lips, D.L.; McMillan, W.D.; Duval, S.; Biggs, T.A.; Keo, H.H. Safety of a non-viral plasmid-encoding dual isoforms of hepatocyte growth factor in critical limb ischemia patients: A phase I study. Gene Ther. 2011, 18, 788-794.

62. Lara-Hernandez, R.; Lozano-Vilardell, P.; Blanes, P.; Torreguitart-Mirada, N.; Galmes, A.; Besalduch, J. Safety and efficacy of therapeutic angiogenesis as a novel treatment in patients with critical limb ischemia. Ann. Vasc. Surg. 2010, 24, 287-294.

63. Mohler, E.R., 3rd.; Treat-Jacobson, D.; Reilly, M.P.; Cunningham, K.E.; Miani, M.; Criqui, M.H.; Hiatt, W.R.; Hirsch, A.T. Utility and barriers to performance of the ankle-brachial index in primary care practice. Vasc. Med. 2004, 9, 253-260.

64. Haigh, K.J.; Bingley, J.; Golledge, J.; Walker, P.J. Barriers to screening and diagnosis of peripheral artery disease by general practitioners. Vasc. Med. 2013, 18, 325-330.

65. Fung, E.T.; Wilson, A.M.; Zhang, F.; Harris, N.; Edwards, K.A.; Olin, J.W.; Cooke, J.P. A biomarker panel for peripheral arterial disease. Vasc. Med. 2008, 13, 217-224.

66. Hiatt, W.R.; Zakharyan, A.; Fung, E.T.; Crutcher, G.; Smith, A.; Stanford, C.; Cooke, J. A validated biomarker panel to identify peripheral artery disease. Vasc. Med. 2012, 17, 386-393. 
67. Kals, J.; Zagura, M.; Serg, M.; Kampus, P.; Zilmer, K.; Unt, E.; Lieberg, J.; Eha, J.; Peetsalu, A.; Zilmer, M. $\beta$-2-microglobulin, a novel biomarker of peripheral arterial disease, independently predicts aortic stiffness in these patients. Scand. J. Clin. Lab. Investig. 2011, 71, 257-263.

68. Wildman, R.P.; Muntner, P.; Chen, J.; Sutton-Tyrrell, K.; He, J. Relation of inflammation to peripheral arterial disease in the national health and nutrition examination survey, 1999-2002. Am. J. Cardiol. 2005, 96, 1579-1583.

69. De Haro Miralles, J.; Martinez-Aguilar, E.; Florez, A.; Varela, C.; Bleda, S.; Acin, F. Nitric oxide: Link between endothelial dysfunction and inflammation in patients with peripheral arterial disease of the lower limbs. Interact. Cardiovasc. Thorac. Surg. 2009, 9, 107-112.

70. Murabito, J.M.; Keyes, M.J.; Guo, C.Y.; Keaney, J.F., Jr.; Vasan, R.S.; D’Agostino, R.B., Sr.; Benjamin, E.J. Cross-sectional relations of multiple inflammatory biomarkers to peripheral arterial disease: The framingham offspring study. Atherosclerosis 2009, 203, 509-514.

71. Gardner, A.W.; Parker, D.E.; Montgomery, P.S.; Sosnowska, D.; Casanegra, A.I.; Esponda, O.L.; Ungvari, Z.; Csiszar, A.; Sonntag, W.E. Impaired vascular endothelial growth factor a and inflammation in patients with peripheral artery disease. Angiology 2014, 65, 683-690.

72. Ho, D.Y.; Cook, N.R.; Britton, K.A.; Kim, E.; Creager, M.A.; Ridker, P.M.; Pradhan, A.D. High-molecular-weight and total adiponectin levels and incident symptomatic peripheral artery disease in women: A prospective investigation. Circulation 2011, 124, 2303-2311.

73. Bertoia, M.L.; Pai, J.K.; Lee, J.H.; Taleb, A.; Joosten, M.M.; Mittleman, M.A.; Yang, X.; Witztum, J.L.; Rimm, E.B.; Tsimikas, S.; et al. Oxidation-specific biomarkers and risk of peripheral artery disease. J. Am. Coll. Cardiol. 2013, 61, 2169-2179.

74. Berger, J.S.; Ballantyne, C.M.; Davidson, M.H.; Johnson, J.L.; Tarka, E.A.; Lawrence, D.; Trivedi, T.; Zalewski, A.; Mohler, E.R., 3rd. Peripheral artery disease, biomarkers, and darapladib. Am. Heart J. 2011, 161, 972-978.

75. Li, S.B.; Yang, F.; Jing, L.; Ma, J.; Jia, Y.D.; Dong, S.Y.; Zheng, W.F.; Zhao, L.S. Correlation between plasma lipoprotein-associated phospholipase A2 and peripheral arterial disease. Exp. Ther. Med. 2013, 5, 1451-1455.

76. Loffredo, L.; Carnevale, R.; Cangemi, R.; Angelico, F.; Augelletti, T.; di Santo, S.; Calabrese, C.M.; della Volpe, L.; Pignatelli, P.; Perri, L.; et al. Nox2 up-regulation is associated with artery dysfunction in patients with peripheral artery disease. Int. J. Cardiol. 2013, 165, 184-192.

77. Silvestro, A.; Scopacasa, F.; Oliva, G.; de Cristofaro, T.; Iuliano, L.; Brevetti, G. Vitamin C prevents endothelial dysfunction induced by acute exercise in patients with intermittent claudication. Atherosclerosis 2002, 165, 277-283.

78. Dong, M.; Jiang, X.; Liao, J.K.; Yan, B.P. Elevated Rho-kinase activity as a marker indicating atherosclerosis and inflammation burden in polyvascular disease patients with concomitant coronary and peripheral arterial disease. Clin. Cardiol. 2013, 36, 347-351.

79. Batinic, K.; Hobaus, C.; Grujicic, M.; Steffan, A.; Jelic, F.; Lorant, D.; Hortenhuber, T.; Hoellerl, F.; Brix, J.M.; Schernthaner, G.; et al. Ykl-40 is elevated in patients with peripheral arterial disease and diabetes or pre-diabetes. Atherosclerosis 2012, 222, 557-563.

80. Moreno, J.A.; Dejouvencel, T.; Labreuche, J.; Smadja, D.M.; Dussiot, M.; Martin-Ventura, J.L.; Egido, J.; Gaussem, P.; Emmerich, J.; Michel, J.B.; et al. Peripheral artery disease is associated with a high cd163/tweak plasma ratio. Arterioscler. Thromb. Vasc. Biol. 2010, 30, 1253-1262. 
81. Rull, A.; Garcia, R.; Fernandez-Sender, L.; Garcia-Heredia, A.; Aragones, G.; Beltran-Debon, R.; Marsillach, J.; Alegret, J.M.; Martin-Paredero, V.; Mackness, B.; et al. Serum paraoxonase-3 concentration is associated with insulin sensitivity in peripheral artery disease and with inflammation in coronary artery disease. Atherosclerosis 2012, 220, 545-551.

82. Signorelli, S.S.; Anzaldi, M.; Fiore, V.; Simili, M.; Puccia, G.; Libra, M.; Malaponte, G.; Neri, S. Patients with unrecognized peripheral arterial disease (PAD) assessed by ankle-brachial index (ABI) present a defined profile of proinflammatory markers compared to healthy subjects. Cytokine 2012, 59, 294-298.

83. Catalano, M.; Cortelazzo, A.; Santi, R.; Contino, L.; Demicheli, M.; Yilmaz, Y.; Zorzetto, M.; Campo, I.; Lanati, N.; Emanuele, E. The Pro12Ala polymorphism of peroxisome proliferator-activated receptor- $\gamma 2$ gene is associated with plasma levels of soluble rage (receptor for advanced glycation endproducts) and the presence of peripheral arterial disease. Clin. Biochem. 2008, 41, 981-985.

84. Stehr, A.; Topel, I.; Muller, S.; Unverdorben, K.; Geissler, E.K.; Kasprzak, P.M.; Schlitt, H.J.; Steinbauer, M. Vegf: A surrogate marker for peripheral vascular disease. Eur. J. Vasc. Endovasc. Surg. 2010, 39, 330-332.

85. Findley, C.M.; Mitchell, R.G.; Duscha, B.D.; Annex, B.H.; Kontos, C.D. Plasma levels of soluble Tie2 and vascular endothelial growth factor distinguish critical limb ischemia from intermittent claudication in patients with peripheral arterial disease. J. Am. Coll. Cardiol. 2008, 52, 387-393.

86. Smadja, D.M.; D’Audigier, C.; Bieche, I.; Evrard, S.; Mauge, L.; Dias, J.V.; Labreuche, J.; Laurendeau, I.; Marsac, B.; Dizier, B.; et al. Thrombospondin-1 is a plasmatic marker of peripheral arterial disease that modulates endothelial progenitor cell angiogenic properties. Arterioscler. Thromb. Vasc. Biol. 2011, 31, 551-559.

87. Morishita, T.; Uzui, H.; Nakano, A.; Mitsuke, Y.; Geshi, T.; Ueda, T.; Lee, J.D. Number of endothelial progenitor cells in peripheral artery disease as a marker of severity and association with pentraxin-3, malondialdehyde-modified low-density lipoprotein and membrane type-1 matrix metalloproteinase. J. Atheroscler. Thromb. 2012, 19, 149-158.

88. Delva, P.; de Marchi, S.; Prior, M.; Degan, M.; Lechi, A.; Trettene, M.; Arosio, E. Endothelial progenitor cells in patients with severe peripheral arterial disease. Endothelium 2008, 15, 246-253.

89. Ridker, P.M.; Stampfer, M.J.; Rifai, N. Novel risk factors for systemic atherosclerosis: A comparison of C-reactive protein, fibrinogen, homocysteine, lipoprotein-a, and standard cholesterol screening as predictors of peripheral arterial disease. JAMA 2001, 285, 2481-2485.

90. Moxon, J.V.; Liu, D.; Wong, G.; Weir, J.M.; Behl-Gilhotra, R.; Bradshaw, B.; Kingwell, B.A.; Meikle, P.J.; Golledge, J. Comparison of the serum lipidome in patients with abdominal aortic aneurysm and peripheral artery disease. Circ. Cardiovasc. Genet. 2014, 7, 71-79.

91. Gueant-Rodriguez, R.M.; Spada, R.; Moreno-Garcia, M.; Anello, G.; Bosco, P.; Lagrost, L.; Romano, A.; Elia, M.; Gueant, J.L. Homocysteine is a determinant of ApoA-I and both are associated with ankle brachial index, in an ambulatory elderly population. Atherosclerosis 2011, $214,480-485$.

92. Homocysteine Lowering Trialists' Collaboration. Lowering blood homocysteine with folic acid based supplements: Meta-analysis of randomised trials. BMJ 1998, 316, 894-898. 
93. Group, V.T.S. The vitatops (vitamins to prevent stroke) trial: Rationale and design of an international, large, simple, randomised trial of homocysteine-lowering multivitamin therapy in patients with recent transient ischaemic attack or stroke. Cerebrovasc. Dis. 2002, 13, 120-126.

94. Loland, K.H.; Bleie, O.; Blix, A.J.; Strand, E.; Ueland, P.M.; Refsum, H.; Ebbing, M.; Nordrehaug, J.E.; Nygard, O. Effect of homocysteine-lowering B vitamin treatment on angiographic progression of coronary artery disease: A western norway B vitamin intervention trial (wenbit) substudy. Am. J. Cardiol. 2010, 105, 1577-1584.

95. Pasqualini, L.; Cortese, C.; Marchesi, S.; Siepi, D.; Pirro, M.; Vaudo, G.; Liberatoscioli, L.; Gnasso, A.; Schillaci, G.; Mannarino, E. Paraoxonase-1 activity modulates endothelial function in patients with peripheral arterial disease. Atherosclerosis 2005, 183, 349-354.

96. Gardner, A.W.; Parker, D.E.; Montgomery, P.S.; Sosnowska, D.; Casanegra, A.I.; Ungvari, Z.; Csiszar, A.; Sonntag, W.E. Gender and racial differences in endothelial oxidative stress and inflammation in patients with symptomatic peripheral artery disease. J. Vasc. Surg. 2014, doi:10.1016/j.jvs.2014.02.045.

97. Pipinos, II; Judge, A.R.; Zhu, Z.; Selsby, J.T.; Swanson, S.A.; Johanning, J.M.; Baxter, B.T.; Lynch, T.G.; Dodd, S.L. Mitochondrial defects and oxidative damage in patients with peripheral arterial disease. Free Radic. Biol. Med. 2006, 41, 262-269.

98. Belch, J.J.; Mackay, I.R.; Hill, A.; Jennings, P.; McCollum, P. Oxidative stress is present in atherosclerotic peripheral arterial disease and further increased by diabetes mellitus. Int. Angiol. 1995, 14, 385-388.

99. Kals, J.; Kampus, P.; Kals, M.; Pulges, A.; Teesalu, R.; Zilmer, K.; Kullisaar, T.; Salum, T.; Eha, J.; Zilmer, M. Inflammation and oxidative stress are associated differently with endothelial function and arterial stiffness in healthy subjects and in patients with atherosclerosis. Scan. J. Clin. Lab. Investig. 2008, 68, 594-601.

100. Gliemann, L.; Nyberg, M.; Hellsten, Y. Nitric oxide and reactive oxygen species in limb vascular function: What is the effect of physical activity? Free Radic. Res. 2014, 48, 71-83.

101. Casey, D.P.; Joyner, M.J. Local control of skeletal muscle blood flow during exercise: Influence of available oxygen. J. Appl. Physiol. 2011, 111, 1527-1538.

102. Loffredo, L.; Pignatelli, P.; Cangemi, R.; Andreozzi, P.; Panico, M.A.; Meloni, V.; Violi, F. Imbalance between nitric oxide generation and oxidative stress in patients with peripheral arterial disease: Effect of an antioxidant treatment. J. Vasc. Surg. 2006, 44, 525-530.

103. Boger, R.H.; Bode-Boger, S.M.; Thiele, W.; Junker, W.; Alexander, K.; Frolich, J.C. Biochemical evidence for impaired nitric oxide synthesis in patients with peripheral arterial occlusive disease. Circulation 1997, 95, 2068-2074.

104. Weiss, D.J.; Casale, G.P.; Koutakis, P.; Nella, A.A.; Swanson, S.A.; Zhu, Z.; Miserlis, D.; Johanning, J.M.; Pipinos, I.I. Oxidative damage and myofiber degeneration in the gastrocnemius of patients with peripheral arterial disease. J. Trans. Med. 2013, 11, 230.

105. Sen, S.; McDonald, S.P.; Coates, P.T.; Bonder, C.S. Endothelial progenitor cells: Novel biomarker and promising cell therapy for cardiovascular disease. Clin. Sci. 2011, 120, 263-283.

106. Shinsato, T.; Miyata, M.; Kubozono, T.; Ikeda, Y.; Fujita, S.; Kuwahata, S.; Akasaki, Y.; Hamasaki, S.; Fujiwara, H.; Tei, C. Waon therapy mobilizes $\mathrm{CD}^{+} 4^{+}$cells and improves peripheral arterial disease. J. Cardiol. 2010, 56, 361-366. 
107. McDermott, M.M.; Guralnik, J.M.; Corsi, A.; Albay, M.; Macchi, C.; Bandinelli, S.; Ferrucci, L. Patterns of inflammation associated with peripheral arterial disease: The inchianti study. Am. Heart J. 2005, 150, 276-281.

108. Cassar, K.; Bachoo, P.; Ford, I.; Greaves, M.; Brittenden, J. Markers of coagulation activation, endothelial stimulation and inflammation in patients with peripheral arterial disease. Eur. J. Vasc. Endovasc. Surg. 2005, 29, 171-176.

109. Owens, C.D.; Ridker, P.M.; Belkin, M.; Hamdan, A.D.; Pomposelli, F.; Logerfo, F.; Creager, M.A.; Conte, M.S. Elevated C-reactive protein levels are associated with postoperative events in patients undergoing lower extremity vein bypass surgery. J. Vasc. Surg. 2007, 45, 2-9; discussion 9.

110. McDermott, M.M.; Liu, K.; Ferrucci, L.; Tian, L.; Guralnik, J.M.; Green, D.; Tan, J.; Liao, Y.; Pearce, W.H.; Schneider, J.R.; et al. Circulating blood markers and functional impairment in peripheral arterial disease. J. Am. Geriatr. Soc. 2008, 56, 1504-1510.

111. McDermott, M.M.; Ferrucci, L.; Liu, K.; Criqui, M.H.; Greenland, P.; Green, D.; Guralnik, J.M.; Ridker, P.M.; Taylor, L.M.; Rifai, N.; et al. D-dimer and inflammatory markers as predictors of functional decline in men and women with and without peripheral arterial disease. J. Am. Geriatr. Soc. 2005, 53, 1688-1696.

112. Owens, C.D.; Kim, J.M.; Hevelone, N.D.; Gasper, W.J.; Belkin, M.; Creager, M.A.; Conte, M.S. An integrated biochemical prediction model of all-cause mortality in patients undergoing lower extremity bypass surgery for advanced peripheral artery disease. J. Vasc. Surg. 2012, 56, 686-695.

113. Stone, P.A.; Schlarb, H.; Campbell, J.E.; Williams, D.; Thompson, S.N.; John, M.; Campbell, J.R.; AbuRahma, A.F. C-reactive protein and brain natriuretic peptide as predictors of adverse events after lower extremity endovascular revascularization. J. Vasc. Surg. 2014, 60, 652-660.

114. Ishii, H.; Kumada, Y.; Toriyama, T.; Aoyama, T.; Takahashi, H.; Murohara, T. Prognostic values of C-reactive protein levels on clinical outcome after endovascular therapy in hemodialysis patients with peripheral artery disease. J. Vasc. Surg. 2010, 52, 854-859.

115. Van Wijk, D.F.; Boekholdt, S.M.; Wareham, N.J.; Ahmadi-Abhari, S.; Kastelein, J.J.; Stroes, E.S.; Khaw, K.T. C-reactive protein, fatal and nonfatal coronary artery disease, stroke, and peripheral artery disease in the prospective EPIC-norfolk cohort study. Arterioscler. Thromb. Vasc. Biol. 2013, 33, 2888-2894.

116. Grenon, S.M.; Chong, K.; Alley, H.; Nosova, E.; Gasper, W.; Hiramoto, J.; Boscardin, W.J.; Owens, C.D. Walking disability in patients with peripheral artery disease is associated with arterial endothelial function. J. Vasc. Surg. 2014, 59, 1025-1034.

117. Cheng, C.H.; Chen, Y.S.; Shu, K.H.; Chang, H.R.; Chou, M.C. Higher serum levels of soluble intracellular cell adhesion molecule-1 and soluble vascular cell adhesion molecule predict peripheral artery disease in haemodialysis patients. Nephrology 2012, 17, 718-724.

118. Haslacher, H.; Perkmann, T.; Gruenewald, J.; Exner, M.; Endler, G.; Scheichenberger, V.; Wagner, O.; Schillinger, M. Plasma myeloperoxidase level and peripheral arterial disease. Eur. J. Clin. Investig. 2012, 42, 463-469.

119. Gremmel, T.; Koppensteiner, R.; Ay, C.; Panzer, S. Residual thrombin generation potential is inversely linked to the occurrence of atherothrombotic events in patients with peripheral arterial disease. Eur. J. Clin. Investig. 2014, 44, 319-324. 
120. Sheu, J.J.; Lin, P.Y.; Sung, P.H.; Chen, Y.C.; Leu, S.; Chen, Y.L.; Tsai, T.H.; Chai, H.T.; Chua, S.; Chang, H.W.; et al. Levels and values of lipoprotein-associated phospholipase A2, galectin-3, RhoA/ROCK, and endothelial progenitor cells in critical limb ischemia: Pharmaco-therapeutic role of cilostazol and clopidogrel combination therapy. J. Transl. Med. 2014, 12, 101.

121. Jouni, H.; Rodeheffer, R.J.; Kullo, I.J. Increased serum $N$-terminal pro-B-type natriuretic peptide levels in patients with medial arterial calcification and poorly compressible leg arteries. Arterioscler. Thromb. Vasc. Biol. 2011, 31, 197-202.

122. Fan, J.; Jouni, H.; Khaleghi, M.; Bailey, K.R.; Kullo, I.J. Serum N-terminal pro-B-type natriuretic peptide levels are associated with functional capacity in patients with peripheral arterial disease. Angiology 2012, 63, 435-442.

123. Kikuchi, R.; Nakamura, K.; MacLauchlan, S.; Ngo, D.T.; Shimizu, I.; Fuster, J.J.; Katanasaka, Y.; Yoshida, S.; Qiu, Y.; Yamaguchi, T.P.; et al. An antiangiogenic isoform of VEGF-A contributes to impaired vascularization in peripheral artery disease. Nat. Med. 2014, 20, 1464-1471.

124. McDermott, M.M.; Lloyd-Jones, D.M. The role of biomarkers and genetics in peripheral arterial disease. J. Am. Coll. Cardiol. 2009, 54, 1228-1237.

125. Virginio, V.W.; Nunes, V.S.; Moura, F.A.; Menezes, F.H.; Andreollo, N.A.; Rogerio, F.; Scherrer, D.Z.; Quintao, E.C.; Nakandakare, E.; Petrucci, O.; et al. Arterial tissue and plasma concentration of enzymatic-driven oxysterols are associated with severe peripheral atherosclerotic disease and systemic inflammatory activity. Free Radic. Res. 2015, 49, 199-203.

126. Owens, C.D.; Kim, J.M.; Hevelone, N.D.; Hamdan, A.; Raffetto, J.D.; Creager, M.A.; Conte, M.S. Novel adipokines, high molecular weight adiponectin and resistin, are associated with outcomes following lower extremity revascularization with autogenous vein. J. Vasc. Surg. 2010, 51, 1152-1159.

127. Hewing, B.; Parathath, S.; Barrett, T.; Chung, W.K.; Astudillo, Y.M.; Hamada, T.; Ramkhelawon, B.; Tallant, T.C.; Yusufishaq, M.S.; Didonato, J.A.; et al. Effects of native and myeloperoxidase-modified apolipoprotein A-I on reverse cholesterol transport and atherosclerosis in mice. Arterioscler. Thromb. Vasc. Biol. 2014, 34, 779-789.

128. Liu, C.; Desikan, R.; Ying, Z.; Gushchina, L.; Kampfrath, T.; Deiuliis, J.; Wang, A.; Xu, X.; Zhong, J.; Rao, X.; et al. Effects of a novel pharmacologic inhibitor of myeloperoxidase in a mouse atherosclerosis model. PLoS ONE 2012, 7, e50767.

129. Van Kimmenade, R.R.; Januzzi, J.L., Jr. Emerging biomarkers in heart failure. Clin. Chem. 2012, $58,127-138$.

130. Madrigal-Matute, J.; Lindholt, J.S.; Fernandez-Garcia, C.E.; Benito-Martin, A.; Burillo, E.; Zalba, G.; Beloqui, O.; Llamas-Granda, P.; Ortiz, A.; Egido, J.; et al. Galectin-3, a biomarker linking oxidative stress and inflammation with the clinical outcomes of patients with atherothrombosis. J. Am. Heart Assoc. 2014, 3, doi:10.1161/JAHA.114.000785.

131. Bachle, A.C.; Morsdorf, P.; Rezaeian, F.; Ong, M.F.; Harder, Y.; Menger, M.D. $N$-acetylcysteine attenuates leukocytic inflammation and microvascular perfusion failure in critically ischemic random pattern flaps. Microvasc. Res. 2011, 82, 28-34.

132. Ozmen, S.; Ayhan, S.; Demir, Y.; Siemionow, M.; Atabay, K. Impact of gradual blood flow increase on ischaemia-reperfusion injury in the rat cremaster microcirculation model. J. Plast. Reconstr. Aesthet. Surg. 2008, 61, 939-948. 
133. Turton, E.P.; Coughlin, P.A.; Kester, R.C.; Scott, D.J. Exercise training reduces the acute inflammatory response associated with claudication. Eur. J. Vasc. Endovasc. Surg. 2002, 23, 309-316.

134. Svensson, P.; de Faire, U.; Niklasson, U.; Hansson, L.O.; Ostergren, J. Plasma NT-probnp concentration is related to ambulatory pulse pressure in peripheral arterial disease. Blood Press. 2005, 14, 99-106.

135. Mueller, T.; Dieplinger, B.; Poelz, W.; Endler, G.; Wagner, O.F.; Haltmayer, M. Amino-terminal pro-B-type natriuretic peptide as predictor of mortality in patients with symptomatic peripheral arterial disease: 5-Year follow-up data from the linz peripheral arterial disease study. Clin. Chem. 2009, 55, 68-77.

136. Marz, W.; Tiran, B.; Seelhorst, U.; Wellnitz, B.; Bauersachs, J.; Winkelmann, B.R.; Boehm, B.O.; Team, L.S. $N$-terminal pro-B-type natriuretic peptide predicts total and cardiovascular mortality in individuals with or without stable coronary artery disease: The ludwigshafen risk and cardiovascular health study. Clin. Chem. 2007, 53, 1075-1083.

137. Lehto, S.; Niskanen, L.; Suhonen, M.; Ronnemaa, T.; Laakso, M. Medial artery calcification. A neglected harbinger of cardiovascular complications in non-insulin-dependent diabetes mellitus. Arterioscler. Thromb. Vasc. Biol. 1996, 16, 978-983.

138. Demer, L.L.; Tintut, Y. Vascular calcification: Pathobiology of a multifaceted disease. Circulation 2008, 117, 2938-2948.

139. O’Neill, W.C.; Han, K.H.; Schneider, T.M.; Hennigar, R.A. Prevalence of nonatheromatous lesions in peripheral arterial disease. Arterioscler. Thromb. Vasc. Biol. 2014, 35, 439-447.

140. Bleda, S.; de Haro, J.; Acin, F.; Varela, C.; Esparza, L. Enhanced vascular endothelial growth factor gene expression in ischaemic skin of critical limb ischaemia patients. Int. J. Vasc. Med. 2012, 2012, 691528.

141. Jones, W.S.; Duscha, B.D.; Robbins, J.L.; Duggan, N.N.; Regensteiner, J.G.; Kraus, W.E.; Hiatt, W.R.; Dokun, A.O.; Annex, B.H. Alteration in angiogenic and anti-angiogenic forms of vascular endothelial growth factor-A in skeletal muscle of patients with intermittent claudication following exercise training. Vasc. Med. 2012, 17, 94-100.

142. Ingber, D.E. Mechanical signaling and the cellular response to extracellular matrix in angiogenesis and cardiovascular physiology. Circ. Res. 2002, 91, 877-887.

143. Silvestre, J.S.; Mallat, Z.; Tamarat, R.; Duriez, M.; Tedgui, A.; Levy, B.I. Regulation of matrix metalloproteinase activity in ischemic tissue by interleukin-10: Role in ischemia-induced angiogenesis. Circ. Res. 2001, 89, 259-264.

144. Yamanaka, M.; Ishikawa, O. Hypoxic conditions decrease the mrna expression of proalpha1(I) and (III) collagens and increase matrix metalloproteinases-1 of dermal fibroblasts in three-dimensional cultures. J. Dermatol. Sci. 2000, 24, 99-104.

145. Baum, O.; Ganster, M.; Baumgartner, I.; Nieselt, K.; Djonov, V. Basement membrane remodeling in skeletal muscles of patients with limb ischemia involves regulation of matrix metalloproteinases and tissue inhibitor of matrix metalloproteinases. J. Vasc. Res. 2007, 44, 202-213.

146. Busti, C.; Falcinelli, E.; Momi, S.; Gresele, P. Matrix metalloproteinases and peripheral arterial disease. Intern. Emerg. Med. 2010, 5, 13-25. 
147. Gagne, P.J.; Tihonov, N.; Li, X.; Glaser, J.; Qiao, J.; Silberstein, M.; Yee, H.; Gagne, E.; Brooks, P. Temporal exposure of cryptic collagen epitopes within ischemic muscle during hindlimb reperfusion. Am. J. Pathol. 2005, 167, 1349-1359.

148. Huang, P.H.; Chen, Y.H.; Wang, C.H.; Chen, J.S.; Tsai, H.Y.; Lin, F.Y.; Lo, W.Y.; Wu, T.C.; Sata, M.; Chen, J.W.; et al. Matrix metalloproteinase-9 is essential for ischemia-induced neovascularization by modulating bone marrow-derived endothelial progenitor cells. Arterioscler. Thromb. Vasc. Biol. 2009, 29, 1179-1184.

149. Szuba, A.; Oka, R.K.; Harada, R.; Cooke, J.P. Limb hemodynamics are not predictive of functional capacity in patients with pad. Vasc. Med. 2006, 11, 155-163.

150. Long, J.; Modrall, J.G.; Parker, B.J.; Swann, A.; Welborn, M.B., 3rd.; Anthony, T. Correlation between ankle-brachial index, symptoms, and health-related quality of life in patients with peripheral vascular disease. J. Vasc. Surg. 2004, 39, 723-727.

151. Krishna, S.M.; Trollope, A.F.; Golledge, J. The relevance of epigenetics to occlusive cerebral and peripheral arterial disease. Clin. Sci. 2015, 128, 537-558.

(C) 2015 by the authors; licensee MDPI, Basel, Switzerland. This article is an open access article distributed under the terms and conditions of the Creative Commons Attribution license (http://creativecommons.org/licenses/by/4.0/). 